\title{
In vivo Imaging $\beta$-cell Function Reveals Two Waves of $\beta$-cell Maturation
}

2 Jia Zhao ${ }^{1}$, Weijian Zong ${ }^{1,5}$, Yi Wu ${ }^{4}$, Jiayu Shen ${ }^{1}$, Dongzhou Gou ${ }^{1}$, Yiwen Zhao ${ }^{1}$, Runlong $\mathrm{Wu}^{3}$, Fuzeng

3 Niu ${ }^{2}$, Xu Wang ${ }^{1}$, Xuan Zheng ${ }^{1}$, Aimin Wang ${ }^{2}$, Yunfeng Zhang ${ }^{3}$, Jing-Wei Xiong ${ }^{1}$, Liangyi Chen ${ }^{1 *}$, Yanmei

$4 \quad \mathrm{Liu}^{1 *}$

Affiliations:

$7 \quad{ }^{1}$ State Key Laboratory of Membrane Biology, Beijing Key Laboratory of Cardiometabolic Molecular

$8 \quad$ Medicine, Institute of Molecular Medicine, Peking University, Beijing 100871, China

$9 \quad{ }^{2}$ State Key Laboratory of Advanced Optical Communication System and Networks, School of Electronics

10 Engineering and Computer Science, Peking University, Beijing 100871, China

$11{ }^{3}$ School of Electronics Engineering and Computer Science, Peking University, Beijing 100871, China

$12 \quad{ }^{4}$ School of Software and Microelectronics, Peking University, Beijing 100871, China

$13{ }^{5}$ China Department of Cognitive Sciences, Institute of Basic Medical Sciences, Beijing 100850, China

14 *Correspondence: yanmeiliu@pku.edu.cn; lychen@pku.edu.cn 


3

4

\section{Abstract}

The insulin-secreting cells generated from stem cells in vitro are less glucose responsive than primary $\beta$-cells. To search for the missing ingredients that are needed for $\beta$-cell maturation, we have longitudinally monitored function of every $\beta$-cell in Tg (ins:Rcamp1.07) zebrafish embryos with a newly-invented two-photon light-sheet microscope. We have shown that $\beta$-cell maturation begins from the islet mantle and propagates to the islet core during the hatching period, coordinated by the islet vascularization. Lower concentration of glucose is optimal to initiate $\beta$-cell maturation, while increased glucose delivery to every cell through microcirculation is required for functional boosting of the $\beta$-cells. Both the initiation and the boosting of $\beta$-cell maturation demands activation of calcineurin/NFAT by glucose. Calcineurin activator combined with glucose promotes mouse neonatal $\beta$-cells cultured in vitro to mature to a functional state similar to adult $\beta$-cells, suggesting a new strategy for improving stem cell-derived $\beta$-like cell function in vitro.

\section{Keywords}

functional maturation of $\beta$-cells in vivo; ins:Rcamp1.07 zebrafish, 2P3A-DSLM; microcirculation; glucose.

5




\section{Introduction}

Pancreatic $\beta$-cells secrete insulin to regulate blood glucose metabolism. An insufficient functional $\beta$ cell mass causes glucose intolerance and diabetes. To generate new therapeutic approaches for diabetes, $\beta$ cell development has been intensively studied during the last two decades. While much has been understood regarding the early development of pancreatic progenitor cells (Pan \& Wright, 2011), the mechanisms regarding the final $\beta$-cell maturation are still poorly defined (Kushner et al, 2014). $\beta$-cells reside in islets that consist of endocrine, vascular, neuronal and mesenchymal cells. Various cues arising from this neurovascular milieu, such as gap junctions, neuronal transmitters, endothelial factors and hormones, have been reported to be involved in $\beta$-cell development (Borden et al, 2013; Carvalho et al, 2010; Cleaver \& Dor, 2012; Omar et al, 2016). The absence of these factors from the culture media that is used by current in vitro differentiation protocols may account for the limited glucose-responsiveness of stem cell-derived $\beta$ like cells (Bruin et al, 2015; Rezania et al, 2014). Hence, knowing how pancreatic $\beta$-cells mature in situ during development may guide the addition of key factors to the culture medium to promote the final maturation of $\beta$-like cells in vitro.

A major difficulty in studying $\beta$-cell maturity in vivo with traditional methods is to evaluate $\beta$-cell function independent of $\beta$-cell mass. Imaging function of individual $\beta$-cells will overcome this problem. The primary function of a mature $\beta$-cell is to quickly secrete the stored insulin in responding to increases of blood glucose concentration. Glucose-triggered $\mathrm{Ca}^{2+}$ influx in pancreatic $\beta$-cells is essential for the insulin secretion, thus often serves as a functional marker to evaluate $\beta$-cell maturity in living organisms (Pagliuca et al, 2014; Rezania et al, 2014). $\mathrm{Ca}^{2+}$ transient in primary $\beta$-cells can be imaged in isolated islets when $\beta$-cells are labelled with genetically encoded fluorescent $\mathrm{Ca}^{2+}$ indicators. However, to image $\mathrm{Ca}^{2+}$ transients in $\beta$-cells in vivo noninvasively remains the unmet challenge due to the non-transparency of the pancreas tissues in mammals.

Here we used zebrafish as the model animal in which $\beta$-cell development is conserved with mammals and their maturation processes can be observed in the transparent, externally developed embryos of zebrafish (Huang et al, 2001). With every $\beta$-cell labelled with Rcamp1.07, a red fluorescent $\mathrm{Ca}^{2+}$ indicator 
in Tg (ins:Rcamp1.07) zebrafish, we use our newly developed high-resolution two-photon three-axis digital scanning light-sheet microscope (2P3A-DSLM) to visualize glucose-stimulated $\mathrm{Ca}^{2+}$ responses in

72 individual $\beta$-cells in vivo. The first glucose-responsive $\beta$-cells appear from the islet mantle at 48 hours post-

73 fertilization (hpf). Based on the $\mathrm{Ca}^{2+}$ transient kinetics, we characterized the glucose-responsive $\beta$-cells into

74 two stages: the initiation and the boosting of the maturation. This early $\beta$-cell maturation of the islet mantle requires low local glucose concentration and is independent of vascularization. With islet vascularization

76 from $60 \mathrm{hpf}$ to $72 \mathrm{hpf}$, increased glucose concentration delivered through islet microcirculation, initiates $\beta$ -

77 cell maturation in the islet core and pushes all glucose-responsive $\beta$-cells towards further maturity. By

78 manipulating with inhibitors, activators and the dominant negative mutant, we demonstrate that the

79 calcineurin/NFAT signaling pathway acts downstream of glucose to initiate, boost and sustain $\beta$-cells maturation. Finally, we showed that neonatal mouse $\beta$-cells within isolated islets can be promoted towards optimal maturity in vitro by the combination of a calcineurin activator and glucose, demonstrating that mammalian $\beta$-cell maturation shares the conserved mechanism. This data also highlights the practicality of direct activation of calcineurin/NFAT in pushing stem cell-derived $\beta$-like cells towards optimal maturity in

84 vitro. 


\section{Results}

\section{Visualization of $\beta$-cell maturation in vivo with 2P3A-DSLM}

To visualize $\beta$-cell function, we created a transgenic zebrafish line, $\operatorname{Tg}$ (ins:Rcamp1.07), in which the red fluorescent calcium indicator Rcamp1.07 (Ohkura et al, 2012) is under the control of the insulin promoter. Rcamp1.07 is expressed exclusively in $\beta$-cells, as confirmed by the cellular co-localization of Rcamp1.07 with EGFP in Tg (ins:Rcamp1.07); Tg (ins:EGFP) double transgenic fish (Huang et al, 2001) (Figure 1Figure Supplement $1 \mathrm{~A}-\mathrm{F}$ ) and with immunofluorescently labelled insulin in $\mathrm{Tg}$ (ins:Rcamp1.07) fish (Figure 1-Figure Supplement 1G-J). Within 5 min after stimulating live $72 \mathrm{hpf}$ Tg (ins:Rcamp1.07) fish embryos with $20 \mathrm{mM}$ glucose, we observed a robust transient increase in the fluorescence intensity of Rcamp1.07 under a wide-field microscope (Figure 1-Figure Supplement 2 and Supplemental Movie 1), indicative of the glucose-stimulated $\mathrm{Ca}^{2+}$ transients in vivo. However, individual $\beta$ cells are hardly discernible under the wide-field (Figure 1-Figure Supplement 2) or a single-photon selective-plane illuminative microscope (1P-SPIM) (Figure 1-Figure Supplement 2). With a two-photon microscope (TPM), we could resolve individual $\beta$-cells in the XY plane, but the cell boundaries along Zaxis were blurred due to the low axial resolution and high scattering of the illumination light in deep tissues. Only with our newly-developed 2P3A-DSLM (Supplemental Movie 2), we could reconstruct a clear threedimensional structure of the islet in live fish embryos (Figure 1A and B, Supplemental Movie 2 and Supplemental Movie 3). To our knowledge, this is the first time to achieve high-resolution in vivo imaging of individual $\beta$-cells and their functions.

By counting insulin-positive cells and glucose-responsive $\beta$-cells at different stages of $\mathrm{Tg}$ (ins:Rcamp1.07); Tg (ins:EGFP) fish embryos, we identified a proliferation of $\beta$-cells during 36-48 hpf, followed by a progressive increase in glucose-responsive $\beta$-cells during the hatching period (Figure $1 \mathrm{C}$ and Figure 1-Figure Supplement 3A). Along with the increase of glucose-responsive $\beta$-cells, mature $\beta$-cell marker MafA positive $\beta$-cells also increased (Figure 1D and E), indicating that by counting glucoseresponsive $\beta$-cells we could evaluate the bona fide maturation process of $\beta$-cells. Because the speed (time to rise) and the maximal amplitude (Max $\Delta \mathrm{F} / \mathrm{F})$ of the glucose-stimulated $\mathrm{Ca}^{2+}$ transients are key parameters 
of $\beta$-cell functionality (Bruin et al, 2015; Rezania et al, 2014), we used them as criteria to evaluate the maturity levels of individual $\beta$-cells in vivo (Figure 1-Figure Supplement 3B). The first glucose-responsive

$114 \beta$-cell appeared at $48 \mathrm{hpf}$ and we defined it to be at the initiation stage of maturation. Compared to glucose-

115 responsive $\beta$-cells at $48 \mathrm{hpf}$, the cells at $56 \mathrm{hpf}$ exhibited faster and larger $\mathrm{Ca}^{2+}$ responses evoked by glucose

116 stimulation on average as many cells have entered the function boosting stage. These average responses

117 were further accelerated and enhanced at $72 \mathrm{hpf}$, when $\beta$-cells responded within $\sim 90 \mathrm{~s}$ of glucose 118 administration with a $\sim 150 \%$ of the maximal amplitude of the evoked $\mathrm{Ca}^{2+}$ transient (Figure $1 \mathrm{~F}$ and $\mathrm{G}$ and

119 Figure 1-Figure Supplement 3C and D). Therefore, with our $\beta$-cell-function visualization zebrafish system, we observed a gradual maturation process of $\beta$-cells in vivo from 48 to $72 \mathrm{hpf}$.

Sequential maturation of $\beta$-cells from the islet mantle to the core is coordinated with islet vascularization

123 Next, we investigated whether islet vascularization affect $\beta$-cell maturation in vivo by labelling both $\beta$-cells and vascular endothelial cells in $\operatorname{Tg}$ (ins:EGFP); $\operatorname{Tg}$ (flk1:mCherry) fish (Wang et al, 2013). We found that blood vessels initiated contacts with the islet mantle from 48 to $60 \mathrm{hpf}$ and further penetrated into the inner layers of the islet from 60 to $72 \mathrm{hpf}$ (Figure 2A and Supplemental Movie 4). Most of the glucose-responsive

$127 \beta$-cells was proximal to blood vessels (Figure 2-Figure Supplement 1A), and their longitudinal increase was paralleled with the increase of $\beta$-cells adjacent to the vessels (Figure $2 \mathrm{~B}$ and Figure 2-Figure Supplement 1B).

As islet vascularization progressed from the mantle to the core, we then examined whether $\beta$-cells in 131 the mantle and $\beta$-cells in the core matured differently during development (Figure 2C). From 48 to $60 \mathrm{hpf}$,

$132 \beta$-cells in the mantle acquired function earlier than those in the core, with more glucose-responsive $\beta$-cells

133 (Figure 2D), higher maximum $\mathrm{Ca}^{2+}$ transients (Figure 2E) and faster responses (Figure 2F). Only during the

134 late hatching period did $\beta$-cells in the core start to mature at an accelerated pace. At 72 hpf, they were 135 indistinguishable from $\beta$-cells in the mantle in terms of all related parameters (Figure $2 \mathrm{D}-\mathrm{F}$ ). Therefore, $\beta$ 136 cells in the mantle mature differently from those in the core both in the initiation time window and function 137 boosting dynamics. 
To explore whether the heterogeneous maturation process is caused by islet vascularization, we endothelial cells or blood cells but a normal number of $\beta$-cells (Figure 2G and Figure 2-Figure Supplement 1C) (Field et al, 2003a). Glucose-responsive $\beta$-cells in $56 \mathrm{hpf}$ cloche embryos were indistinguishable from those in age-matched controls (Figure $2 \mathrm{H}$ and I). At $72 \mathrm{hpf}$, in contrast, cloche mutants had fewer glucoseresponsive $\beta$-cells in the islet core and exhibited smaller maximum $\mathrm{Ca}^{2+}$ transients in responding $\beta$-cells than the controls (Figure $2 \mathrm{H}$ and I). Without islet microcirculation, $\beta$-cells of cloche mutants stayed in a maturation state similar to that in $60 \mathrm{hpf}$ control embryos (Figure 3-Figure Supplement 1). Therefore, $\beta$ cells mature in two waves in vivo: first, mantle $\beta$-cells acquire glucose responsiveness independent of islet vascularization during 48-60 hpf; next, islet vascularization initiates the maturation of the $\beta$-cells in the islet core and promotes all glucose-responsive $\beta$-cells to further mature during 60-72 hpf. To test whether blood circulation or endothelial cells provide the key inductive factor, we stopped the blood circulation with 2,3butanedione monoxime (2,3-BDM) (Bartman et al, 2004) for 9 hours in ins:Rcampl.07 embryos at either the early or the late hatching period. Despite intact islet vascularization after the circulation blockade (data not shown), 2,3-BDM treatment inhibited $\beta$-cell maturation to a similar extent as that of cloche mutants (Figure 2H and I). Therefore, blood circulation per se, but not endothelial cells, provides the key inductive signal for $\beta$-cells in the islet core to initiate and further promote their maturation.

\section{Increased glucose delivered by the microcirculation controls sequential $\beta$-cell maturation}

Glucose, the major nutrient in the circulation system, is known to regulate embryonic pancreatic endocrine cell differentiation in vitro (Guillemain et al, 2007). To explore whether glucose could be the inductive signal for $\beta$-cell maturation, we used 3-mercaptopicolinic acid (3-MPA), an inhibitor of gluconeogenic phosphoenolpyruvate carboxykinase 1 ( $p c k 1$ ), to suppress endogenous glucose synthesis (Jurczyk et al, 2011). This leads to severe and equal suppression of the maturation of $\beta$-cells in the mantle and the core of 
glucose ( $3 \mathrm{mM}, 5 \mathrm{mM}, 8 \mathrm{mM}$ or $20 \mathrm{mM}$ ). From 44 to $53 \mathrm{hpf}, 3 \mathrm{mM}$ glucose completely rescued the $\beta$-cell maturation defects caused by 3-MPA treatment, whereas $8 \mathrm{mM}$ glucose only partially rescued the number of glucose-responsive $\beta$-cells in the islet mantle (Figure 3A and C). In contrast, from 60 to $69 \mathrm{hpf}$, we had to increase the exogenous glucose to $8 \mathrm{mM}$ to fully rescue the phenotype (Figure 3A-D), and $3 \mathrm{mM}$ glucose was insufficient to maintain a normal functional $\beta$-cell mass in the islet core (Figure 3A-D). During the entire hatching period, $20 \mathrm{mM}$ glucose performed worst in the rescue experiments, indicative of glucotoxicity at this concentration, as reported in mammalian $\beta$-cells previously (Poitout et al, 2006). Therefore, different from vascularization, glucose is required for both $\beta$-cells in the islet core and those in the mantle for maturation initiation, function boosting and maintenance. On the other hand, our results also demonstrate that islet vascularization significantly increases the amount of glucose delivered to islet $\beta$-cells, initiating the $\beta$-cell maturation in the core and boosting all the glucose-responsive $\beta$-cells to be more functional.

\section{Calcineurin/NFAT activated by glucose drives $\beta$ cells maturation}

Next, we tried to identify the master signalling pathway triggered by glucose. Recently, activation of calcineurin/NFAT by a glucokinase activator was proposed to mediate $\beta$-cells development and function in mice (Goodyer et al, 2012a; Heit et al, 2006). To test whether calcineurin/NFAT act as the primary maturation signalling pathway downstream of glucose, we examined the $\beta$-cell maturity after incubating the embryos with calcineurin/NFAT inhibitors and activators. From 36 to $48 \mathrm{hpf}$, either inhibition of calcineurin with FK506 (Goodyer et al, 2012a; Heit, 2007) or suppression of gluconeogenesis with 3-MPA prevented the appearance of the first glucose-responsive $\beta$-cell without affecting $\beta$-cell proliferation (Figure 4A). In contrast, inhibition of the mTORC pathway with rapamycin abolished $\beta$-cell proliferation without affecting its maturation (Figure 4A and B and Supplemental Movie 6). These results suggest that glucose activated calcineurin/NFAT is essential for $\beta$-cell maturation initiation.

Inhibiting calcineurin or NFAT (with VIVIT (Demozay et al, 2011)) during the hatching period also significantly reduced the number of glucose-responsive $\beta$-cells and their maximal $\mathrm{Ca}^{2+}$ response amplitude (Figure 4B and Figure 4-Figure Supplement 1). Interestingly, the $\beta$-cells that had been already responsive 
to glucose before the inhibitor treatment were reverted to less matured states (Figure 2-Figure Supplement 2), suggesting that calcineurin/NFAT continuous activation is required for the maintenance of the maturation state. On the other hand, direct activation of calcineurin with chlorogenic acid (CGA) (Tong et al, 2007) or NFAT with ProINDY (Ogawa et al, 2010) readily rescued the defective functional maturation of $\beta$-cells caused by 3-MPA (Figure 4B, Figure 4-Figure Supplement 1 and Supplemental Movie 6). These results suggest a necessary and sufficient role of calcineurin/NFAT in mediating the effect of glucose in initiating, boosting and sustaining $\beta$-cell maturation.

To provide further evidence for such a hypothesis, we created and applied a dominant-negative zebrafish calcineurin $A(d n-z C n A)$. As $C n A$ is highly conserved with $81 \%$ identity in amino acids between zebrafish and human, we constructed $d n-z C n A$ based on the strategy of generating dominant-negative human calcineurin A ( $d n-h C n A)$ (Faure et al, 2007). In Tg(ins:Rcamp1.07) genetic background, we generated transient transgenic zebrafish embryos $\operatorname{Tg}($ ins:EGFP-GSG-T2A- $d n-z C n A)$, in which the $d n-$ $z C n A$ is co-expressed with EGFP with a $G S G-T 2 A$ linker under the drive of the insulin promoter. Under TPM, we observed $75.8 \% \pm 2.5$ Rcamp1.07 positive cells co-express EGFP, indicating 70\%-80\% $\beta$-cells express $d n-z C n A$ in $\operatorname{Tg}($ ins:Rcamp1.07); $\operatorname{Tg}($ ins:EGFP-GSG-T2A-dnCnA) double transgenic fish (Figure 4C). When stimulating with $20 \mathrm{mM}$ glucose, we observed a decreased number of glucose-responsive $\beta$ cells and smaller maximum $\mathrm{Ca}^{2+}$ transients in the responding $\beta$-cells in the $72 \mathrm{hpf}$ embryos expressing $d n$ $z C n A$ compared with the age-matched controls (Figure 4D and E). The first glucose-responsive $\beta$-cells still appeared at the $48 \mathrm{hpf}$ embryos expressing $d n-z C n A$, but all these glucose-responsive $\beta$-cells were EGFP negative, indicative of not expressing $d n-z C n A$ in these $\beta$-cells. Taken together, these results are consistent with the results of pharmacological treatments with calcineurin/NFAT inhibitors, providing convincing evidence that calcineurin/NFAT drives $\beta$-cell maturation.

Finally, inhibiting calcineurin or suppressing gluconeogenesis severely reduced the number of MafApositive $\beta$-cells at $72 \mathrm{hpf}$ to a similar extent. Direct activating calcineurin, on the other hand, fully rescued the number of MafA-positive $\beta$-cells in 3-MPA treated fish (Figure 4F and G). Thus, glucose activates the calcineurin/NFAT signalling pathway to initiate, boost, and sustain the whole process of $\beta$-cell maturation, possibly via upregulation of MafA. 
Direct activating calcineurin promotes neonatal $\beta$-cells towards optimal maturity in isolated mouse islets

221

\section{in vitro}

The failure for the core $\beta$-cells to mature in the cloche mutants and 2,3-BDM-treated embryos could be due to reduced glucose delivery to the islet centre. Indeed, in isolated mouse islets that had no microcirculation, we found a gradually reduced glucose transported into $\beta$-cells of the inner layers (Figure 5A-C). To explore whether the requirement of optimal glucose for $\beta$-cell maturation could be bypassed in vitro, we tried to activate calcineurin/NFAT to promote $\beta$-cell maturation in isolated neonatal mouse islets. As we have known, the $\beta$-cells of neonatal mouse islets respond poorly to glucose and need more than one week to mature in vivo (Blum et al, 2012b). We cultured the neonatal islets from postnatal day 0 (P0) mice for 3 days in media supplemented with different concentrations of glucose, in the absence or presence of the calcineurin activator CGA, and evaluated their maturity according to the glucose stimulation index (GSI). Among the different glucose concentrations tested, $11 \mathrm{mM}$ glucose in the culture media was the best in transforming neonatal $\beta$-cells in islets to be more glucose-responsive (GSI $=13.0 \pm 1.3$, Figure $5 \mathrm{D}$ and $\mathrm{E})$. Supporting a conserved role of calcineurin in mouse $\beta$-cell maturation, combining CGA in the culture media greatly enhanced the GSIs of islets cultured at a glucose concentration ranging from $5.6 \mathrm{mM}$ to $11 \mathrm{mM}$. Neonatal islets cultured at $11 \mathrm{mM}$ glucose and $56.48 \mu \mathrm{M}$ CGA exhibited a GSI of $26.5 \pm 4.8(\mathrm{n}=12)$, similar to that of adult mouse islets cultured at $11 \mathrm{mM}$ glucose $(27.3 \pm 3.4, \mathrm{n}=4, \mathrm{p}=0.79)$ (Figure 5D and E). On the other hand, calcineurin inhibitor FK506 notably reduced the GSI of the neonatal islets cultured at $11 \mathrm{mM}$ glucose (Figure 5D and E). As compared to more than one week needed for P0 $\beta$-cells to mature in vivo (Blum et al, 2012b), our results indicate a greatly accelerated maturation process in vitro by using small molecule activators of calcineurin/NFAT, which may also be used to push stem-cell derived immature $\beta$-cells towards optimal maturity in vitro. 


\section{Discussion}

244 Here, by taking advantage of the advanced microscopy 2P3A-DSLM technique, we were able to resolve individual $\beta$-cells and monitor their functions in an intact living organism. Spatiotemporally, we characterized the maturation of $\beta$-cells in vivo as two waves that are differentially affected by islet microcirculation: before islet vascularization, locally synthesized glucose initiates the early $\beta$-cell maturation from the islet mantle only; islet vascularization significantly increases the amount of glucose delivered to islet $\beta$-cells, initiating maturation of $\beta$-cells in the islet core and pushing all glucose-responsive $\beta$-cells towards further maturity (Figure 6).

With classical methods such as immunofluorescence microscopy to observe the expression of maturation markers in fixed samples or ELISA to measure the GSI, $\beta$-cells maturation is usually evaluated as a whole. Whether all $\beta$-cells in the islets mature at a synchronized pace remains mysterious. By longitudinal imaging $\beta$-cell function in vivo, we have discovered the apparent heterogeneity of the maturation process inside the islets. In addition, our data also suggests that the dosage effect of glucose on maturation initiation is different from that on function boosting. Suppression of the in vivo glucose production with 3-MPA at the early hatching period did not prevent all the mantle $\beta$-cells from entering maturation initiation, but limited their glucose-evoked $\mathrm{Ca}^{2+}$ responses to the lowest level as those in the core $\beta$-cells (Figure 4B). Therefore, the glucose concentrations needed for the conversion of glucose-nonresponsive $\beta$-cells to glucose-responsive $\beta$-cells may be lower than those required for further boosting $\beta$ cell function thereafter. Consistently, the glucose concentration needed for the further maturation of $\beta$-cells from $55 \mathrm{hpf}$ to $72 \mathrm{hpf}$ increases significantly (Figure 3), reinforcing the concept of a delicately regulated glucose concentration for different steps of $\beta$-cell maturation. As zebrafish and mammals share many similarities during pancreatic islet development (Supplemental Table 1), an increasing dosage requirement of glucose for $\beta$-cells maturation in vivo is very likely to be a conserved mechanism. Consistent with this hypothesis, the plasma glucose level in fetal rodents is relatively low, but starts to increase just before birth and progressively reaches a plateau (above $4 \mathrm{mM}$ ) after P2 (Rozzo et al, 2009). From P6 to P20, the plasma glucose further gradually increases from $6 \mathrm{mM}$ to $12 \mathrm{mM}$ (Aguayo-Mazzucato et al, 2006). This period is 
maturation (Hole et al, 1988; Reinert et al, 2014; Rozzo et al, 2009). Therefore, $\beta$-cell maturation in rodents may also require a dynamically increased glucose concentration, coordinated by islet vascularization. Multiple signalling pathways are known to be activated by glucose to regulate gene transcriptions. These "master switches" include calcineurin/NFAT (Lawrence et al, 2002), the AMP-activated protein kinase, carbohydrate response element-binding protein (Iizuka \& Horikawa, 2008; Vaulont et al, 2000), and the hexosamine biosynthetic pathway (Vanderford et al, 2007). Although implication of calcineurin/NFAT in $\beta$-cell maturation has been proposed in mice (Goodyer et al, 2012a; Heit et al, 2006), their critical role on the $\beta$-cell proliferation mask their effect on the $\beta$-cell maturation. For instance, $\beta$-cell specific calcineurin b1 knock-out mice (RIP-Cre; $\left.C n b 1^{\Delta \mathcal{S}}\right)$ did not exhibit any phenotypes until 8-week after birth when $\beta$-cell mass starts to reduce (Heit et al, 2006). In contrast, pancreatic endocrine progenitor cell specific calcineurin bl knock-out mice (Ngn3-Cre; $\mathrm{Cnbl}^{\text {Slox }}$ ) developed glucose intolerance and diabetes at P20, accompanied with a more than $80 \%$ reduction in $\beta$-cell mass at P26 (Goodyer et al, 2012a). These data strongly support a critical role of calcineurin/NFAT in $\beta$-cell precursor's differentiation and $\beta$ cell proliferation, but obscure its role in $\beta$-cell maturation. The failure to establish a solid link between calcineurin/NFAT and $\beta$-cell maturation may explain why manipulation of this pathway has never been tried to enhance stem cell-derived $\beta$-like cells maturation in vitro. By imaging $\beta$-cell function acquisition and enhancement in zebrafish in vivo, we demonstrate that calcineurin/NFAT, downstream of increasing glucose concentrations delivered by the blood circulation, is essential for the initiation, boosting and maintenance of $\beta$-cell maturation. The mechanism is inter-species conserved, as activating calcineurin/NFAT could also bypass the deficit of microcirculation in isolated mouse islets, accelerate the ex vivo maturation of neonatal mouse $\beta$-cells (Figure 5D and $\mathrm{E}$ ). Currently, different research groups use a variety of glucose concentrations, ranged from $2.8 \mathrm{mM}$ to $20 \mathrm{mM}$, in the last stage to push $\beta$-like cells derived from stem cells in vitro to be more functional competent, as nobody knows the ideal condition for the $\beta$-cell maturation (Bruin et al, 2015). Obviously, blood vessels are absent from these $\beta$-like cell clusters, either. Based on our data, we argue that the lack of spatiotemporal precise glucose delivery to all $\beta$-like cells may contribute significantly to their limited glucose responsiveness. On this regard, direct activation 
296 of calcineurin/NFAT with small molecules may confer a previously unexplored strategy to push these $\beta$ -

297 like cell clusters toward maximal maturity in vitro.

$298 \quad$ Future imaging of panoramic $\beta$-cell mass and function in vivo in zebrafish with our system may

299 unravel mechanisms of other important but obscure processes in islet biology, such as regeneration, cell

300 identity or functional changes during disease progression. Understanding these principals may shed light

301 on the ultimate cell replacement therapy to treat diabetes. 


\section{Materials and Methods}

\section{Transgenic zebrafish generation}

The $\operatorname{Tg}($ ins:Rcamp1.07) reporter zebrafish line was generated using meganuclease-mediated transgenesis as previously described (Soroldoni et al, 2009). Briefly, zebrafish BAC_CH211_69I14 (BACPAC Resources Center), which contains the zebrafish insulin gene, was modified using Red/ET recombineering technology to replace the coding sequence of insulin with Rcampl.07 (Fu et al, 2010). Rcamp1.07-tagged $\mathrm{BAC}$ underwent a second round of recombineering for the subcloning of the modified chromosomal locus into a plasmid backbone containing two I-SceI meganuclease sites. The following primers were used for BAC modification:

Forward primer: 5' ATGTTTTTGATTGACAGAGATTGTATGTGTGTGTTTGTGTCAGTGTGA CCCGCCACCATGGGTTCTCATC.

Reverse primer: 5' CCTGTGTGCAAACAGGTGTTTCTGGCATCGGCGGTGGTCAAATCTCTTC AGGCAGATCGTCAGTCAG.

$$
\text { And for subcloning: }
$$

Forward primer: 5' AGTCCATTAAATAATATCTTGTAGAATTATGTTTTTAAAAAGTACCAAT GCCGTAGGGATAACAGGGTAATTTAAGC.

\section{Reverse primer: 5' CAACTTTTTCACAAACACTGACCAAAACAAGCTACATGTTTTAGAGGC}

\section{ATTAGGGATAACAGGGTAATTGCACTG.}

The resulting constructs were co-injected with I-SceI meganuclease (Roche) at a DNA concentration of $100 \mathrm{ng} / \mu \mathrm{l}$ into one-cell stage zebrafish embryos. These F0 embryos were screened for the transient expression of Rcamp1.07 in the pancreatic islet at $48 \mathrm{hpf}$ using a fluorescence stereomicroscope. The positive F0 founders were raised to adults and were screened by visual inspection of their F1 progenies from outcrossing with the wild-type $\mathrm{AB}$ strain. Based on the intensity of the fluorescence signal, one founder was selected, and subsequent generations were propagated and expanded.

The $\operatorname{Tg}($ ins:EGFP-GSG-T2A-dn-zCnA) zebrafish line was generated using Tol2 transposase RNAmediated transgenesis as previously described. Briefly, $d n-z C n A$ was constructed by deleting the autoinhibitory and the calmodulin-binding domains through introducing a stop codon at the N396 amino acid 
and by mutating the histidine at the position 152 , a phosphatase-active site, to glutamine. The GSG-T2A peptide was used to separating EGFP and dn-zCnA elements. The EGFP-GSG-T2A-dn-zCnA fragment was cloned downstream of $2.1 \mathrm{~kb}$ of the proximal insulin promoter and into a Tol2 plasmid by ClonExpress system. The final construct was injected along with Tol2 transposase RNA into $\operatorname{Tg}($ ins:Rcamp1.07) eggs to generate mosaic $\operatorname{Tg}($ ins:EGFP-GSG-T2A-dn-zCnA); $\operatorname{Tg}($ ins:Rcamp1.07) F0 fish for imaging analysis.

\section{Zebrafish care and handling}

The wild-type $\mathrm{AB}$ strain and transgenic fish were maintained and handled according to the institutional guidelines of animal usage and maintenance of Peking University. $\operatorname{Tg}($ ins:EGFP) fish were from Dr. Lin Shuo at UCLA; $T g(f l k 1: m C h e r r y)$ fish were from Dr. Zhang Bo at PKU; $T g(f l k 1: G F P)$ fish were from Dr. Chen Jau-Nian at UCLA. Tg(ins:Rcamp1.07) was crossed with heterozygous cloche $^{m 39}$ to obtain Tg(ins:Rcamp1.07); cloche ${ }^{m 39} /+$ zebrafish. Tg(ins:Rcamp1.07); cloche $^{m 39} /$ cloche $^{m 39}$ embryos from the crossing of $T g$ (ins:Rcamp1.07); cloche $e^{m 39} /+$ with cloche $^{m 39} /+$ fish were used for the imaging experiments. For imaging, $0.002 \%$ phenylthiourea (PTU, Sigma) was added at $12 \mathrm{hpf}$ to prevent pigment synthesis. Prior to live imaging, embryos were anaesthetized with $0.01 \%$ tricaine (Sigma).

\section{Pharmacological treatment. Heterozygous $\operatorname{Tg}$ (ins:Rcamp1.07) embryos were used for} pharmacological treatment and imaging analysis. All chemicals were prepared as high-concentration stocks and were diluted in E3 medium to final concentrations for treatment, which were carefully selected to be non-toxic and effective. To test the pharmacological effect of the chemicals on the functional maturation of pancreatic $\beta$ cells, the embryos were treated with each chemical for 9 hours, either from 44 to 53 hpf or from 60 to $69 \mathrm{hpf}$; the embryos then recovered for $3 \mathrm{~h}$ after E3 medium was used to completely wash out the chemical, and imaging analysis was carried out at $56 \mathrm{hpf}$ or at $72 \mathrm{hpf}$, respectively. For the pharmacological treatment of zebrafish embryos, $10 \mathrm{mM}$ 2,3-butanedione monoxime (2,3-BDM, Sigma) was used to block blood circulation; $3 \mathrm{mM}$ 3-mercaptopicolinic acid (3-MPA, Santa Cruz) was used to inhibit endogenous glucose production; $141.2 \mu \mathrm{M}$ chlorogenic acid (CGA, Sigma) or $10 \mu \mathrm{M}$ FK506 (Invivogen) was used to activate or inhibit calcineurin, respectively; and $2.5 \mu \mathrm{M}$ ProINDY (Tocris) or 20 $\mu \mathrm{M}$ VIVIT peptide (Tocris) was used to activate or inhibit NFAT, respectively. 


\section{Wide field and 2P3A-DSLM imaging}

358 For the wide field time-lapse imaging, the images were captured using an Olympus inverted fluorescence microscope with a 10×/0.4 objective. D-Glucose stock solution was added to the E3 medium for a final concentration of $20 \mathrm{mM}$ during stimulation. The images were collected with MetaMorph software and analysed with Fiji software.

High-resolution images of pancreatic $\beta$-cells and blood vessels in live zebrafish embryos were captured with 2P3A-DSLM equipped with two 40×/0.8 water lenses as previously described (Zong et al, 2015). then immersed in a homemade chamber with E3 medium containing $0.01 \%$ tricaine. D-glucose stock was added to the $\mathrm{E} 3$ medium to reach a final concentration of $20 \mathrm{mM}$ to stimulate the fish embryos. For the 2D time-lapse imaging experiments that were used for statistical analysis, the islet was optically sectioned into 5-6 layers to ensure that the calcium transients of all $\beta$-cells within the islet were recorded. For fast volumetric imaging and reconstruction of calcium transients within the whole islet, the islet was optically sectioned into 25 layers. Each layer was captured 5 times with an 8-ms exposure time and was averaged as one single image. Images were collected by the HCImage software (Hamamatsu) and processed with R-L deconvolution by Fiji software. The volumetric calcium transients were reconstructed with Amira software (FEI).

\section{Comparison among 1P-SPIM, TPM and 2P3A-DSLM in 3D imaging of islet in vivo}

376 For 1P-SPIM imaging, we used a homemade SPIM setup equipped with a 40×/0.8 water lens. For TPM 377 imaging, we used a fast resonant-scanned TPM equipped with a 40×/0.8 water lens. The same $72 \mathrm{hpf}$ 378 zebrafish samples were sequentially imaged with 1P-SPIM, TPM and 2P3A-DSLM. Under each 379 configuration, the whole islet was optically sectioned by 100 planes (z-step: $500 \mathrm{~nm}$ ) with an exposure time 380 of $150 \mathrm{~ms}$ per frame. Images were collected by HCImage software and processed with R-L deconvolution 381 by Fiji software. 


\section{Whole-mount immunofluorescence and confocal imaging}

The embryos were fixed in $4 \%$ paraformaldehyde (PFA, AppliChem) at $4{ }^{\circ} \mathrm{C}$ overnight. After the PFA was washed away, the embryos were dehydrated using a series of methanol $(25 \%, 50 \%, 75 \%$ and $100 \%)$ and stored at $-20^{\circ} \mathrm{C}$. When necessary, the embryos were rehydrated using a series of methanol $(100 \%, 75 \%, 50 \%$ and 25\%), permeabilized in Proteinase K (10 $\mu \mathrm{g} / \mathrm{ml}$, TransGen), washed in PBST (PBS + 0.1\% Tween-20) and then fixed again in 4\% PFA at room temperature (RT). After being blocked with PBST containing $0.2 \%$ bovine serum albumin (BSA, AppliChem) and 5\% fetal bovine serum (Gibco) for $1 \mathrm{~h}$ at RT, the embryos were incubated with primary antibodies overnight at $4{ }^{\circ} \mathrm{C}$. Then, secondary antibodies were applied at $4{ }^{\circ} \mathrm{C}$ overnight after thorough washing. The primary antibodies included monoclonal rat anti-mCherry antibody (1:200, Thermo, used to detect Rcamp1.07), polyclonal guinea pig anti-insulin antibody (1:200, Dako) and polyclonal rabbit anti-MafA antibody (1: 50, Sigma). The secondary antibodies were Alexa Fluor 568 goat anti-rat IgG (1: 500, Thermo), DyLight 488 goat anti-guinea pig IgG (1: 500, Thermo), DyLight 550 goat anti-guinea pig IgG (1: 500, Thermo) and DyLight 488 goat anti-rabbit IgG (1: 500, Thermo). Before imaging, the samples were dehydrated in $100 \%$ methanol and mounted in mounting solution containing one volume of benzyl alcohol (Sigma) and two volumes of benzyl benzoate (Sigma) with their right side facing the coverslips. The images were collected by MetaMorph software using an Olympus spinning-disc confocal microscope and processed by Fiji software.

\section{Embedding and cryostat sectioning}

The embryos were fixed in $4 \%$ PFA at $4{ }^{\circ} \mathrm{C}$ overnight. After being washed, the embryos were dehydrated in 30\% sucrose (Sigma) and then transferred to embedding chambers filled with OCT compound (Tissue Tek®). After embedding, the samples were frozen in liquid nitrogen as soon as possible. Sectioning was performed using a Leica CM1900 Cryostat set to $10 \mu \mathrm{m}$ thickness and a $-25^{\circ} \mathrm{C}$ chamber temperature. The sections were collected and kept at $-20{ }^{\circ} \mathrm{C}$ in a sealed slide box. Immunofluorescence staining was performed as described above. For nuclear staining, the samples were incubated with $2 \mu \mathrm{g} / \mathrm{ml}$ DAPI (Solarbio) for 10 minutes. After an extensive wash, the samples were mounted in $80 \%$ glycerol (Sigma) and imaged using an Olympus spinning-disc confocal microscope. 
412 For this study, 8-week-old mouse islets were isolated and cultured in RPMI 1640 medium containing $7 \mathrm{mM}$ 413 glucose for 2 days (Wang et al, 2016). Before imaging, the islets were washed twice with Krebs (KRB) 414 buffer $\left(129 \mathrm{mM} \mathrm{NaCl}, 4.7 \mathrm{mM} \mathrm{KCl}, 1 \mathrm{mM} \mathrm{CaCl}_{2} \cdot 2 \mathrm{H}_{2} \mathrm{O}, 1.2 \mathrm{mM} \mathrm{MgSO}_{4}, 1.2 \mathrm{mM} \mathrm{KH}_{2} \mathrm{PO}_{4}, 5 \mathrm{mM}\right.$ $415 \mathrm{NaHCO}_{3}, 10 \mathrm{mM}$ HEPES, 0.5\% BSA) and then pre-incubated in $7 \mathrm{mM}$ 2-(N-(7-nitrobenz-2-oxa-1,3-diazol416 4-yl)Amino)-2-deoxyglucose (2-NBDG) dissolved in $\mathrm{KRB}$ buffer for 10 min at $37^{\circ} \mathrm{C}$. After thoroughly 417 washing, z-stack images of the islets were captured with a TPM (Zeiss 710). The 2-NBDG signal was excited at $920 \mathrm{~nm}$ and collected between $510 \mathrm{~nm}$ and $540 \mathrm{~nm}$.

In vitro culture of mouse islets and measurement of glucose-stimulated insulin secretion

421 Adult islets from 8-week-old mice were isolated as previously described (Wang et al, 2016). For P0 mouse islet isolation, pancreata were dissected directly without perfusion and digested with $0.5 \mathrm{mg} / \mathrm{ml}$ Collagenase P (Roche). The isolated islets were cultured for 3 days in RPMI1640 media containing different concentrations of glucose ( $0.5 \mathrm{mM}, 2.8 \mathrm{mM}, 5.6 \mathrm{mM}, 7 \mathrm{mM}, 11 \mathrm{mM}, 15 \mathrm{mM}$ and $20 \mathrm{mM})$ combined or not combined with CGA $(56.48 \mu \mathrm{M})$. The culture medium was changed every day. 10 islets with similar sizes were selected and pre-incubated in $\mathrm{KRB}$ buffer for 3 hours at $37^{\circ} \mathrm{C}$ in a $5 \% \mathrm{CO}_{2}$ incubator. The islets were then transferred into low glucose $(3 \mathrm{mM}) \mathrm{KRB}$ buffer and incubated for 1 hour at $37^{\circ} \mathrm{C}, 5 \% \mathrm{CO}_{2}$. The supernatant was collected for measuring basal insulin secretion. The same islets were further transferred into high glucose $(20 \mathrm{mM}) \mathrm{KRB}$ buffer for 1 hour incubation at $37^{\circ} \mathrm{C}, 5 \% \mathrm{CO}_{2}$. The supernatant was collected, stored at $-20^{\circ} \mathrm{C}$ and later the insulin content was measured with the Rat/Mouse insulin ELISA kit

431 (Millipore).

\section{Statistical analysis}

434 All data were analysed using GraphPad Prism 6 software. Average results were displayed as the mean 
436 distributed datasets or Mann-Whitney rank sum test for non-single Gaussian-distributed datasets. The

437 asterisks * and ** denote statistical significance with $p$ values less than 0.05 or 0.01 , respectively.

438

439 Study approval

440 Generation of the transgenic zebrafish lines, in vivo imaging of the living zebrafish embryos, and all the

441 other experiments about zebrafish and mouse islets were approved by the IACUC of Peking University.

442

443

444

445

446

447

448

449

450

451

452

453

454

455

456

457 
7

\section{Acknowledgments}

We thank Dr. Lin Shuo, Dr. Zhang Bo, Dr. Chen Jau-Nian and Dr. Liu Feng for sharing the fish lines with us. We thank Dr. Liao Bo-Kai and Ms. Meng Liying for technique consultant and assistant. This work was supported by grants from the National Science Foundation of China $(81222020,31221002,31327901$, 31570839, 3142800018 and 31301186), the Natural Science Foundation of Beijing Municipality (7121008, 7152079), the Major State Basic Research Program of P.R. China (2013CB531200), and the National Key Technology R\&D Program (SQ2011SF11B01041).

\section{Author contributions}

Y. L. conceived the project. L.C. and Y.L. directed the study. J.Z., L.C. and Y.L. designed the research. J.Z., W.Z., Y.W., J.S., D.G., Y.Z., R.W., F.N., X.W., X.Z., A.W., Y.Z., and Y.L. performed the experiments. J.X. provided critical fish lines and fish facility. J.Z., L.C. and Y.L. analyzed the data and wrote the manuscript.

\section{Competing interests}

The authors declare that they have no conflict of interest.

78




\section{References}

485

486

487

488

Aguayo-Mazzucato C, Sanchez-Soto C, Godinez-Puig V, Gutierrez-Ospina G, Hiriart M (2006) Restructuring of Pancreatic Islets and Insulin Secretion in a Postnatal Critical Window. Plos One 1

Avolio F, Pfeifer A, Courtney M, Gjerne E, Ben-Othman N, Vieira A, Druelle N, Faurite B, Collombat P (2013) From Pancreas Morphogenesis to beta-Cell Regeneration. Curr Top Dev Biol 106: 217-238

Bartman T, Walsh EC, Wen KK, McKane M, Ren J, Alexander J, Rubenstein PA, Stainier DY (2004) Early myocardial function affects endocardial cushion development in zebrafish. PLoS Biol 2: E129

Blum B, Hrvatin S, Schuetz C, Bonal C, Rezania A, Melton DA (2012a) Functional beta-cell maturation is marked by an increased glucose threshold and by expression of urocortin 3. Nat Biotechnol 30: 261-264

Blum B, Hrvatin SS, Schuetz C, Bonal C, Rezania A, Melton DA (2012b) Functional beta-cell maturation is marked by an increased glucose threshold and by expression of urocortin 3. Nat Biotechnol 30: 261-264

Borden P, Houtz J, Leach SD, Kuruvilla R (2013) Sympathetic innervation during development is necessary for pancreatic islet architecture and functional maturation. Cell Rep 4: 287-301

Bruin JE, Rezania A, Kieffer TJ (2015) Replacing and safeguarding pancreatic beta cells for diabetes. Sci Transl Med 7: 316 ps323

Carvalho CP, Barbosa HC, Britan A, Santos-Silva JC, Boschero AC, Meda P, Collares-Buzato CB (2010) Beta cell coupling and connexin expression change during the functional maturation of rat pancreatic islets. Diabetologia 53: $1428-1437$

Cleaver O, Dor Y (2012) Vascular instruction of pancreas development. Development 139: 2833-2843

Demozay D, Tsunekawa S, Briaud I, Shah R, Rhodes CJ (2011) Specific glucose-induced control of insulin receptor substrate-2 expression is mediated via $\mathrm{Ca} 2+-$ dependent calcineurin/NFAT signaling in primary pancreatic islet betacells. Diabetes 60: 2892-2902

Faure C, Corvol JC, Toutant M, Valjent E, Hvalby O, Jensen V, El Messari S, Corsi JM, Kadare G, Girault JA (2007) Calcineurin is essential for depolarization-induced nuclear translocation and tyrosine phosphorylation of PYK2 in neurons. J Cell Sci 120: 3034-3044

Field HA, Dong PD, Beis D, Stainier DY (2003a) Formation of the digestive system in zebrafish. II. Pancreas morphogenesis. Dev Biol 261: 197-208 
Field HA, Dong PDS, Beis D, Stainier DYR (2003b) Formation of the digestive system in zebrafish. II. Pancreas morphogenesis. Dev Biol 261: 197-208

Fu J, Teucher M, Anastassiadis K, Skarnes W, Stewart AF (2010) A recombineering pipeline to make conditional targeting constructs. Methods Enzymol 477: 125-144

Goodyer WR, Gu X, Liu Y, Bottino R, Crabtree GR, Kim SK (2012a) Neonatal beta cell development in mice and humans is regulated by calcineurin/NFAT. Dev Cell 23: 21-34

Goodyer WR, Gu XY, Liu YH, Bottino R, Crabtree GR, Kim SK (2012b) Neonatal beta Cell Development in Mice and Humans Is Regulated by Calcineurin/NFAT. Dev Cell 23: 21-34

Guillemain G, Filhoulaud G, Da Silva-Xavier G, Rutter GA, Scharfmann R (2007) Glucose is necessary for embryonic pancreatic endocrine cell differentiation. J Biol Chem 282: 15228-15237

Heit JJ (2007) Calcineurin/NFAT signaling in the beta-cell: From diabetes to new therapeutics. Bioessays 29: 10111021

Heit JJ, Apelqvist AA, Gu X, Winslow MM, Neilson JR, Crabtree GR, Kim SK (2006) Calcineurin/NFAT signalling regulates pancreatic beta-cell growth and function. Nature 443: 345-349

Hole RL, Piansmith MCM, Sharp GWG (1988) Development of the Biphasic Response to Glucose in Fetal and Neonatal Rat Pancreas. Am J Physiol 254: E167-E174

Huang H, Vogel SS, Liu N, Melton DA, Lin S (2001) Analysis of pancreatic development in living transgenic zebrafish embryos. Mol Cell Endocrinol 177: 117-124

Iizuka K, Horikawa Y (2008) ChREBP: A glucose-activated transcription factor involved in the development of metabolic syndrome. Endocr J 55: 617-624

Jurczyk A, Roy N, Bajwa R, Gut P, Lipson K, Yang C, Covassin L, Racki WJ, Rossini AA, Phillips N, Stainier DY, Greiner DL, Brehm MA, Bortell R, diIorio P (2011) Dynamic glucoregulation and mammalian-like responses to metabolic and developmental disruption in zebrafish. Gen Comp Endocrinol 170: 334-345

Kushner JA, MacDonald PE, Atkinson MA (2014) Stem Cells to Insulin Secreting Cells: Two Steps Forward and Now a Time to Pause? Cell Stem Cell 15: 535-536

Lawrence MC, Bhatt HS, Easom RA (2002) NFAT regulates insulin gene promoter activity in response to synergistic pathways induced by glucose and glucagon-like peptide-1. Diabetes 51: 691-698 
Nair G, Hebrok M (2015) Islet formation in mice and men: lessons for the generation of functional insulin-producing beta-cells from human pluripotent stem cells. Curr Opin Genet Dev 32: 171-180

Ogawa Y, Nonaka Y, Goto T, Ohnishi E, Hiramatsu T, Kii I, Yoshida M, Ikura T, Onogi H, Shibuya H, Hosoya T, Ito N, Hagiwara M (2010) Development of a novel selective inhibitor of the Down syndrome-related kinase Dyrk1A. Nat Commun 1: 86

Ohkura M, Sasaki T, Kobayashi C, Ikegaya Y, Nakai J (2012) An improved genetically encoded red fluorescent Ca2+ indicator for detecting optically evoked action potentials. Plos One 7: e39933

Omar B, Ahlkvist L, Yamada Y, Seino Y, Ahren B (2016) Incretin hormone receptors are required for normal beta cell development and function in female mice. Peptides 79: 58-65

Pagliuca FW, Millman JR, Gurtler M, Segel M, Van Dervort A, Ryu JH, Peterson QP, Greiner D, Melton DA (2014) Generation of Functional Human Pancreatic beta Cells In Vitro. Cell 159: 428-439

Pan FC, Wright C (2011) Pancreas organogenesis: from bud to plexus to gland. Dev Dyn 240: 530-565

Poitout V, Hagman D, Stein R, Artner I, Robertson RP, Harmon JS (2006) Regulation of the insulin gene by glucose and fatty acids. $J$ Nutr 136: 873-876

Reinert RB, Cai Q, Hong JY, Plank JL, Aamodt K, Prasad N, Aramandla R, Dai CH, Levy SE, Pozzi A, Labosky PA, Wright CVE, Brissova M, Powers AC (2014) Vascular endothelial growth factor coordinates islet innervation via vascular scaffolding. Development 141: 1480-1491

Rezania A, Bruin JE, Arora P, Rubin A, Batushansky I, Asadi A, O'Dwyer S, Quiskamp N, Mojibian M, Albrecht T, Yang YH, Johnson JD, Kieffer TJ (2014) Reversal of diabetes with insulin-producing cells derived in vitro from human pluripotent stem cells. Nat Biotechnol 32: 1121-1133

Rozzo A, Meneghel-Rozzo T, Delakorda SL, Yang SB, Rupnik M (2009) Exocytosis of Insulin In Vivo Maturation of Mouse Endocrine Pancreas. Ann Ny Acad Sci 1152: 53-62

Shah SR, Esni F, Jakub A, Paredes J, Lath N, Malek M, Potoka DA, Prasadan K, Mastroberardino PG, Shiota C, Guo P, Miller KA, Hackam DJ, Burns RC, Tulachan SS, Gittes GK (2011) Embryonic mouse blood flow and oxygen correlate with early pancreatic differentiation. Dev Biol 349: 342-349

Shih HP, Wang A, Sander M (2013) Pancreas Organogenesis: From Lineage Determination to Morphogenesis. Annu Rev Cell Dev Bi 29: 81-105

Soroldoni D, Hogan BM, Oates AC (2009) Simple and efficient transgenesis with meganuclease constructs in zebrafish. Methods Mol Biol 546: 117-130 
605

606

607

608

609

610

611

612

613

614

615

616

617

618

619

620

621

622

623

624

625

626

627

628

629

630

631

632

633

634

635

636

637

638

639

640

641

Tehrani Z, Lin S (2011) Endocrine pancreas development in zebrafish. Cell Cycle 10: 3466-3472

Tiso N, Moro E, Argenton F (2009) Zebrafish pancreas development. Mol Cell Endocrinol 312: 24-30

Tong L, Song Y, Jia Z, Zhang W, Wei Q (2007) Calmodulin-dependent activation of calcineurin by chlorogenic acid. IUBMB Life 59: 402-407

Tsuji N, Ninov N, Delawary M, Osman S, Roh AS, Gut P, Stainier DYR (2014) Whole Organism High Content Screening Identifies Stimulators of Pancreatic Beta-Cell Proliferation. Plos One 9

Vanderford NL, Andrali SS, Ozcan S (2007) Glucose induces MafA expression in pancreatic beta cell lines via the hexosamine biosynthetic pathway. J Biol Chem 282: 1577-1584

Vaulont S, Vasseur-Cognet M, Kahn A (2000) Glucose regulation of gene transcription. J Biol Chem 275: 3155531558

Wang L, Liu T, Xu L, Gao Y, Wei Y, Duan C, Chen GQ, Lin S, Patient R, Zhang B, Hong D, Liu F (2013) Fev regulates hematopoietic stem cell development via ERK signaling. Blood 122: 367-375

Wang Y, Han C, Zhu W, Wu Z, Liu Y, Chen L (2016) An optical method to evaluate both mass and functional competence of pancreatic alpha- and beta-cells. J Cell Sci 129: 2462-2471

Yamaoka T, Itakura M (1999) Development of pancreatic islets (Review). Int J Mol Med 3: 247-261

Zhou Q, Law AC, Rajagopal J, Anderson WJ, Gray PA, Melton DA (2007) A multipotent progenitor domain guides pancreatic organogenesis. Dev Cell 13: 103-114

Zong W, Zhao J, Chen X, Lin Y, Ren H, Zhang Y, Fan M, Zhou Z, Cheng H, Sun Y, Chen L (2015) Large-field highresolution two-photon digital scanned light-sheet microscopy. Cell Res 25: 254-257 


\section{Figure Legends}

Figure 1. Visualization and characterization of the $\beta$-cell maturation process in vivo by 2P3A-DSLM. (A) An abbreviated scheme of the dual-colour 2P3A-DSLM imaging system. (B) 3D-projection of all pancreatic $\beta$-cells in a living 72 hpf $T g$ (ins:Rcamp1.07) zebrafish embryo. The different colours in the colour bar represent different depth of the islet. $(C)$ The increasing rates of total $\beta$-cell and glucoseresponsive $\beta$-cell numbers at different stages from 28 to 74 hpf. $\mathrm{n}=10-16$ embryos for each stage. $(D)$ Whole-mount immunofluorescent labelling of insulin and MafA in embryos at 48, 56 and $72 \mathrm{hpf}$ (left). Representative immunofluorescent labelling images of cryostat sections of $72 \mathrm{hpf}$ zebrafish embryos (right). (E) Quantifications of MafA-positive $\beta$-cells and glucose-responsive $\beta$-cells at the indicated stages. $\mathrm{n}=4$ 6 embryos for each condition. ${ }^{* *} P<0.01$. (F) An illustration of glucose-responsive (red) and glucose nonresponsive (green) $\beta$-cells of the islets in live Tg(ins:Rcamp1.07) Tg(ins:EGFP) embryos at 48, 56 and 72 hpf. $(G)$ Average traces of glucose-triggered maximum $\mathrm{Ca}^{2+}$ transients at the indicated stages. $\mathrm{n}=10-16$ embryos for each condition. (Scale bars: $10 \mu \mathrm{m}$; scale bars apply to $D$ and $F$.) See also Figure 1-Figure Supplement 1, 2 and 3, and Supplemental Movies 1, 2 and 3.

Figure 2. Sequential maturation of $\beta$-cells in the mantle and the core of the islet from the early to the late hatching period, which is coordinated with islet microcirculation. (A) Representative 3Dprojections of $\beta$-cells (green) and neighbouring blood vessels (red) at different stages in live Tg(ins:EGFP); $T g(f l k 1: m C h e r r y)$ embryos. (B) The comparison of the increasing rate of $\beta$-cells adjacent to the vascular endothelium (VE) with that of glucose-responsive $\beta$-cells at different stages from 28 to $74 \mathrm{hpf}$. $\mathrm{n}=4-7$ embryos for each stage. $(C)$ An illumination of classification of $\beta$-cells into two populations, cells in the mantle (green) and in the core (red) of the islet. (D) Time-dependent increases in the glucoseresponsive $\beta$-cells from the mantle (dark) and the core (red) of the islet. $\mathrm{n}=10-16$ embryos for each stage. $(E-F)$ Time-dependent increases in the maximum amplitude $(E)$ and the speed $(F)$ of the glucose-triggered $\mathrm{Ca}^{2+}$ transients in $\beta$-cells from the mantle and the core of the islet. n $=10-16$ embryos for each stage in $E$ and $F$. (G) Representative 3D-projections of the $\beta$-cells (red) and neighbouring blood vessels (green) in live 
wild-type or cloche ${ }^{-/} \operatorname{Tg}($ ins:Rcamp1.07); $T g(f l k 1: G F P)$ embryos. (H-I) Numbers of glucose-responsive $\beta$ cells $(H)$ and their maximal $\mathrm{Ca}^{2+}$ responses to glucose $(I)$ in the mantle and core of the islets in cloche $e^{-/-}$ mutants and 2,3-BDM-treated embryos. $\mathrm{n}=4-6$ embryos for each stage in $H$ and $I .{ }^{*} P<0.05,{ }^{*} P<0.01$. (Scale bars: $10 \mu \mathrm{m}$; scale bars apply to $A, C$ and $G$.) See also Figure 2-Figure Supplement 1 and Supplemental Movie 4.

Figure 3. Different concentrations of glucose are required for inducing optimal $\beta$-cell maturation at different maturation stages. $(A-B)$ Numbers of glucose-responsive $\beta$-cells $(A)$ and their maximal $\mathrm{Ca}^{2+}$ responses to glucose $(B)$ in the mantle and in the core of the islets from embryos treated with 3-MPA and different concentrations of glucose. $\mathrm{n}=4-8$ embryos for each condition in A and B. ${ }^{\star} P<0.05,{ }^{* *} P<0.01$. ( $C$ $D$ ) The recovery ratios of glucose-responsive $\beta$-cells $(C)$ and their maximal $\mathrm{Ca}^{2+}$ responses to glucose $(D)$ by different concentrations of exogenous glucose while the endogenous glucose production was inhibited by 3-MPA. The ratios are represented as the normalized numbers of glucose-responsive $\beta$-cells or the normalized maximal amplitudes of the calcium transients relative to those of the control embryos. $n=4-8$ embryos for each condition in $C$ and $D .{ }^{*} P<0.05,{ }^{* *} P<0.01$; ns, not significant. See also Figure 3-Figure Supplement 1 and Supplemental Movie 5.

Figure 4. Calcineurin/NFAT acts as the master regulator downstream of glucose to initiate and sustain $\beta$-cell maturation. (A) Numbers of total $\beta$-cells (left) and glucose-responsive $\beta$-cells (right) in 48 hpf embryos that had been treated with the indicated reagents. $n=4-8$ embryos for each condition. ${ }^{*} P<0.05$, ${ }^{\star \star} P<0.01$; ns, not significant. $(B)$ Numbers of glucose-responsive $\beta$-cells (left) and their maximal amplitudes of $\mathrm{Ca}^{2+}$ transients in glucose-responsive $\beta$-cells (right) in the mantle and core of the islet in 56 hpf embryos that had been treated with the indicated reagents. $n=5-9$ embryos for each condition. ${ }^{*} P<0.05$, ${ }^{\star \star} P<0.01$; ns, not significant. (C) Representative TPM images of Rcamp1.07 (left), EGFP (middle) and the merged images (right) of the same islet cells in $72 \mathrm{hpf}$ living Tg(ins:Rcamp1.07);Tg(ins:EGFP-GSG-T2A$d n-z C n A$ ) embryos. ( $D-E)$ Numbers of glucose-responsive $\beta$-cells $(D)$ and their maximal $\mathrm{Ca}^{2+}$ responses to glucose $(E)$ in the age-matched control and the embryos expressing $d n-z C n A$ at 48 and 72 hpf. $\mathrm{n}=3-4$ 
696

697

698

699

700

701

702

703

704

705

706

707

708

709

710

711

712

713

714

715

716

717

718

719

720

721

embryos for each stage in $D$ and $E .{ }^{*} P<0.05,{ }^{*} P<0.01$; ns, not significant. $(F)$ Immunofluorescent labelling of insulin and MafA in $72 \mathrm{hpf}$ embryos that had been treated with the indicated reagents. $(G)$ Quantifications of MafA-positive $\beta$-cells in 72 hpf embryos that had been treated with the indicated reagents. $n=4-6$ embryos for each condition. ${ }^{* *} P<0.01$; ns, not significant. (Scale bars: $10 \mu \mathrm{m}$; scale bars apply to $C$ and $F$.) See also Figure 4-Figure Supplement 1 and Supplemental Movie 6.

Figure 5. Direct activating calcineurin readily pushes neonatal mouse $\beta$-cells in isolated islets towards optimal maturation in vitro. (A) Significantly reduced glucose uptake in the core of the islets in vitro represented as the TPM image of an islet pre-incubated with 7mM 2-NBDG (a fluorescent D-glucose analog) for $10 \mathrm{~min}$. (B) Profile plot of fluorescent intensity versus distance indicated in A (white line with arrow). (C) Normalized fluorescent intensity of $\beta$-cells in each layer of the islet in A. ${ }^{\star} P<0.05,{ }^{*} P<0.01$. (D) Glucose-stimulated insulin secretion from neonatal mouse islets stimulated with low and high glucose, after isolation from P0 mice and culturing in vitro for 3 days in different media. Insulin secretion of adult islets from 8-week-old mice after 3 days of culturing in media with $11 \mathrm{mM}$ glucose is also shown. $\mathrm{n}=4-10$ experiments for each condition. ${ }^{*} P<0.05,{ }^{* *} P<0.01$; ns, not significant. (E) GSIs of the neonatal islets and the adult islets described in $D . \mathrm{n}=4-10$ experiments for each condition. ${ }^{* \star} P<0.01$; ns, not significant.

Figure 6. An inter-species conserved model of microcirculation-coordinated, glucose-triggered, calcineurin/NFAT-dependent $\boldsymbol{\beta}$-cell maturation in vivo. At approximately $48 \mathrm{hpf}$, locally synthesized glucose $(\sim 3 \mathrm{mM})$ initiates glucose responsiveness of $\beta$-cells exclusively in the islet mantle. After $60 \mathrm{hpf}$, islet vascularization enables the efficient delivery of glucose through the blood circulation to the islet core to trigger the internal cells to mature. Both the mantle and the core $\beta$-cells sense a more than 2 -fold increase in glucose $(\sim 8 \mathrm{mM})$, which pushes them to further maturity. Maturation of all $\beta$-cells in the islet depends on the glucose-activated calcineurin/NFAT pathway, the master regulators of MafA expression and $\beta$-cell function acquisition. 
Figure 1-Figure Supplement 1. Specific expression of Rcamp1.07 in pancreatic $\beta$-cells in Tg(ins:Rcamp1.07) zebrafish. (A) An illustration shows the protocol for generating the $T g$ (ins:Rcamp1.07) fish line. (B) Tg(ins:Rcamp1.07)-positive fish with Rcamp1.07 fluorescent signals in the islet region under a wide field microscope. $(C$-E) Representative dual-colour 2P3A-DSLM images of Rcamp1.07 (C), EGFP $(D)$ and the merged images $(E)$ of the same islet cells in 72 hpf living Tg(ins:Rcamp1.07); $T g($ ins:EGFP) embryos. $(F)$ The co-localization of Rcamp1.07 and EGFP was analysed by Mander's intensity correlation (Fiji plugin), and the Pearson's $\mathrm{R}$ value was 0.93. (G-J) Representative confocal images of immunofluorescently labelled Rcamp1.07 $(G)$, insulin $(H)$, DAPI labelling $(I)$ and the merged images $(J)$ of the same islet cells in 72 hpf $T g($ ins:Rcamp1.07) embryos. (Scale bars: $10 \mu \mathrm{m}$; scale bars apply to $C$ - $E$ and $G-J$.

Figure 1-Figure Supplement 2. Visualization of glucose-stimulated calcium transients in $\beta$-cells in living $\boldsymbol{T g}$ (ins:Rcamp1.07) embryos under a wide field microscope. $T g($ ins:Rcamp1.07) embryos were embedded in a $1 \%$ ultra-pure agarose cylinder and immersed in a $35 \mathrm{~mm}$ plastic chamber filled with E3 medium containing $0.01 \%$ tricaine. Images were captured once every minute with a $150 \mathrm{~ms}$ exposure time. At the 10 min time point, $20 \mathrm{mM}$ glucose was added. (A) Representative images of Rcamp1.07 in the pancreatic islet of a $72 \mathrm{hpf}$ live $\operatorname{Tg}$ (ins:Rcamp1.07) embryo after stimulation with $20 \mathrm{mM}$ glucose. Montages started from $3 \mathrm{~min}$ after glucose application and are shown at 3-min intervals. Arrows indicate two representative regions within the islet. $(B)$ Time courses of calcium transients from the regions marked in A. (Scale bar: $50 \mu \mathrm{m}$.)

\section{Figure 1-Figure Supplement 3. Quantification of glucose-responsive $\beta$-cells and evaluation of their} maturation states. $(A)$ Quantification of glucose-responsive $\beta$-cells at different stages from 24 to $72 \mathrm{hpf}$. ${ }^{*} P<0.05$. (B) An illustration of the two parameters describing the kinetics of glucose-stimulated $\mathrm{Ca}^{2+}$ transients: the maximum amplitude (Max $\Delta \mathrm{F} / \mathrm{F})$ and the speed of the $\mathrm{Ca}^{2+}$ response (time to rise); the latter was defined as the delay between the time of glucose application and the time when the increase in cytoplasmic $\mathrm{Ca}^{2+}$ reached half of the Max $\Delta \mathrm{F} / \mathrm{F}$. (C) Average speeds (time to rise) of the $\mathrm{Ca}^{2+}$ responses in 
glucose-responsive $\beta$ cells from 48 to 72 hpf. ${ }^{\star} P<0.05$. (D) Average maximum amplitudes of $\mathrm{Ca}^{2+}$ transients in glucose-responsive $\beta$-cells from 48 to $72 \mathrm{hpf} .{ }^{* *} P<0.01$.

Figure 2-Figure Supplement 1. Islet vascularization does not affect the total $\beta$-cell number, but correlates with the acquisition of glucose-responsiveness of $\boldsymbol{\beta}$-cells. $(A)$ Quantification of glucoseresponsive $\beta$-cells adjacent or non-adjacent to blood vessels from 44 to $72 \mathrm{hpf}$. $\mathrm{n}=4-7$ embryos for each condition. (B) Quantification of pancreatic $\beta$-cells adjacent or non-adjacent to VE cells from 36 to $72 \mathrm{hpf}$. $\mathrm{n}=8$ embryos for each condition. ${ }^{*} P<0.05,{ }^{*} P<0.01$. (C) Quantification of total $\beta$-cells in wild-type or cloche $^{-/}$embryos at 48, 56, and 72 hpf. $\mathrm{n}=3-4$ embryos for each condition.

Figure 3-Figure Supplement 1. Blocking blood circulation at the late hatching period stops $\beta$-cells at a functional status equivalent to $60 \mathrm{hpf}$ embryos, whereas inhibiting the glucose/calcineurin/NFAT pathway severely reverts glucose-responsive $\beta$-cells to less matured states. $(A)$ The experimental design for $B$ and $C$ in which $T g$ (ins:Rcamp1.07) embryos at $60 \mathrm{hpf}$ were treated with different reagents for $9 \mathrm{~h}$ and then washed in the normal E3 medium for $3 \mathrm{~h}$ before imaging. $(B-C)$ Quantification of glucose-responsive $\beta$-cells $(B)$ and their maximal $\Delta \mathrm{F} / \mathrm{F}(C)$ in 60 hpf controls $(\mathrm{n}=4), 72 \mathrm{hpf}$ cloche $e^{-/-}$mutants $(\mathrm{n}=4)$ and 72 hpf embryos that had been treated with 2,3-BDM $(n=4)$, 3-MPA $(n=10)$, FK506 $(n=6)$ or VIVIT $(n=$ 6). ${ }^{*} P<0.05,{ }^{*} P<0.01$; ns, not significant.

\section{Figure 4-Figure Supplement 1. Glucose activates calcineurin/NFAT to finish the final maturation of} pancreatic $\boldsymbol{\beta}$-cells during the late hatching period. $\operatorname{Tg}$ (ins:Rcamp1.07) embryos at $60 \mathrm{hpf}$ were treated with different reagents for $9 \mathrm{~h}$ and then washed in the normal E3 medium for $3 \mathrm{~h}$ before imaging. $(A-B)$ Quantification of glucose-responsive $\beta$-cells $(A)$ and their maximal $\Delta \mathrm{F} / \mathrm{F}$ in glucose-responsive $\beta$-cells $(B)$ in the mantle and core of the islet in DMSO-treated controls, rapamycin-treated embryos, 3-MPA-treated embryos, FK506-treated embryos, VIVIT-treated embryos, 3-MPA and CGA co-treated embryos and 3MPA and ProINDY co-treated embryos at 72 hpf. $\mathrm{n}=5-9$ embryos for each condition. ${ }^{*} P<0.05,{ }^{* *} P<0.01$; ns, not significant. 
777 Supplemental Table 1. Comparison of the critical events and the time windows in zebrafish and

778

779

Supplemental Movie 1. Time-lapse images of glucose-stimulated calcium transients in pancreatic $\beta$ cells in a 72 hpf $\operatorname{Tg}$ (ins:Rcamp1.07) embryo under a wide field microscope.

Supplemental Movie 2. Scheme of the dual-colour 2P3A-DSLM and comparison among 1P-SPIM, TPM and 2P3A-DSLM in islet 3D imaging of live zebrafish.

Supplemental Movie 3. Representative time-lapse volumetric reconstruction of glucose-stimulated calcium transients in all pancreatic $\beta$-cells from 72 hpf $\mathbf{T g}$ (ins:Rcamp1.07) embryos observed under the 2P3A-DSLM.

Supplemental Movie 4. Volumetric reconstruction of pancreatic $\beta$-cells and their nearby blood vessels in living $\operatorname{Tg}$ (ins:EGFP); $\operatorname{Tg}(f l k 1$ :mCherry) embryos from $36 \mathrm{hpf}$ to $72 \mathrm{hpf}$.

Supplemental Movie 5. Representative time-lapse volumetric reconstruction of glucose-stimulated calcium transients in all pancreatic $\beta$-cells from 72 hpf $T g$ (ins:Rcamp1.07) embryos that had been treated with 3-MPA.

Supplemental Movie 6. Representative time-lapse volumetric reconstruction of glucose-stimulated calcium transients in all pancreatic $\beta$-cells from $72 \mathrm{hpf}$ Tg(ins:Rcamp1.07) embryos that had been cotreated with 3-MPA and CGA. 
bioRxiv preprint doi: https://doi.org/10.1101/159673; this version posted July 5, 2017. The copyright holder for this preprint (which was not certified by peer review) is the author/funder, who has granted bioRxiv a license to display the preprint in perpetuity. It is made available under aCC-BY 4.0 International license.

803

804

805

806

807

808

809

810

811

812 
A

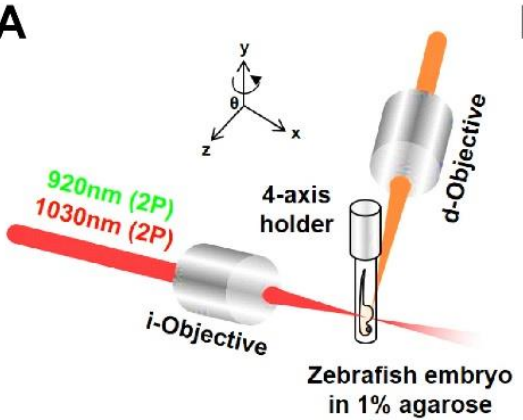

D $\quad 48 \mathrm{hpf}$
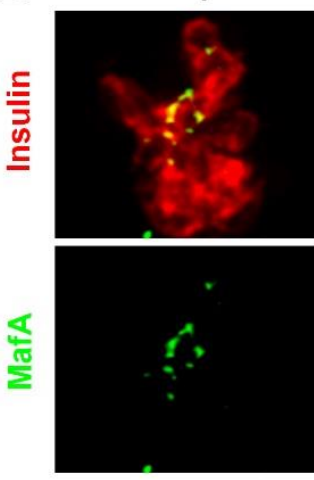

$\mathbf{F}$

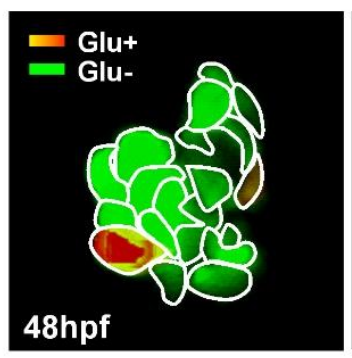

56hpf
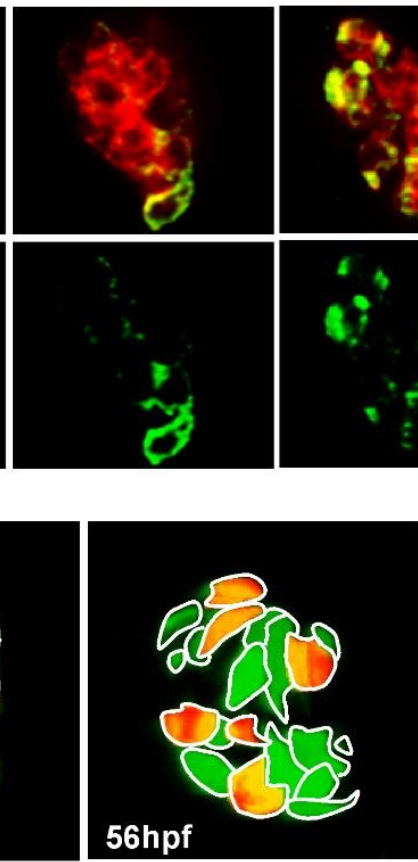

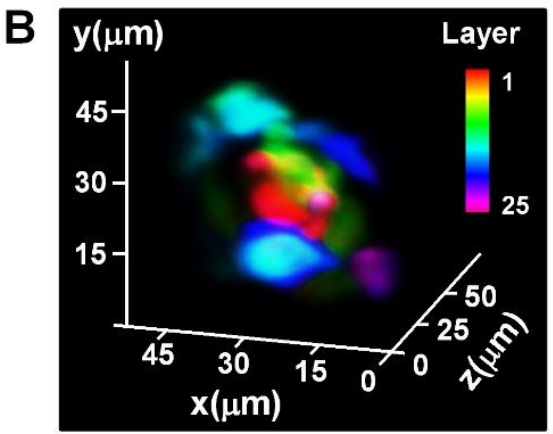

72hpf
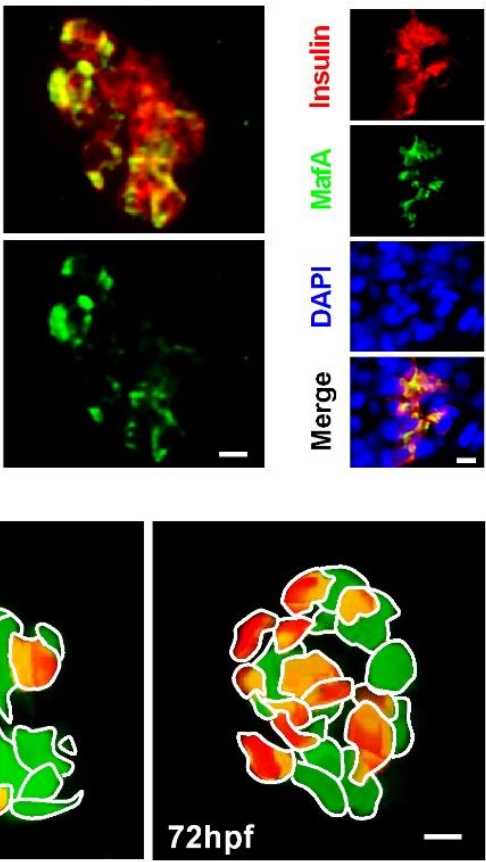

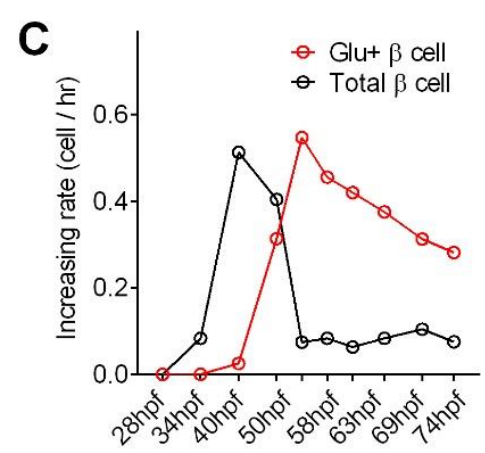

E

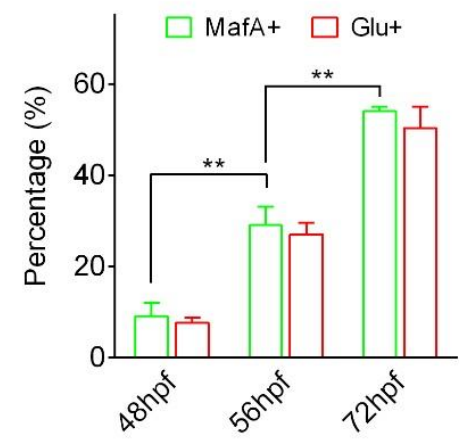

G

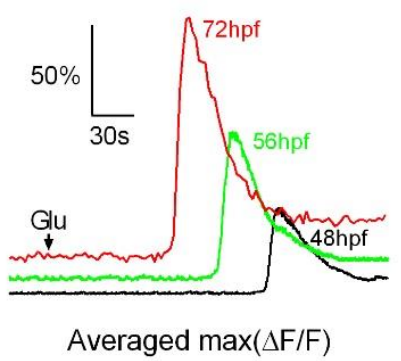


A

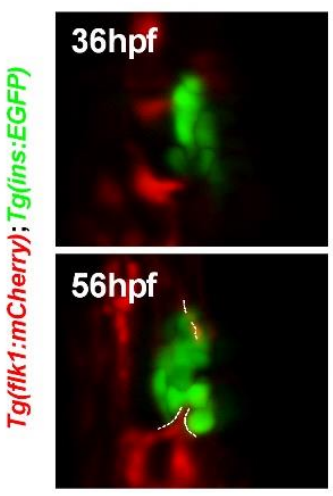

C

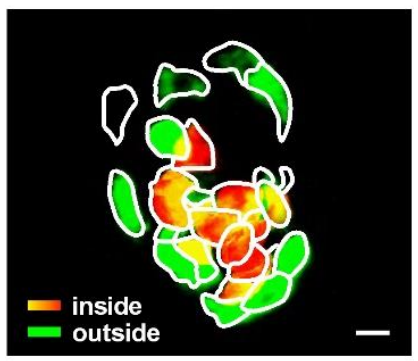

G

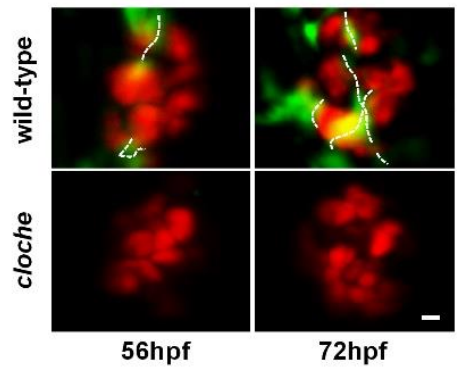

$60 h p f$
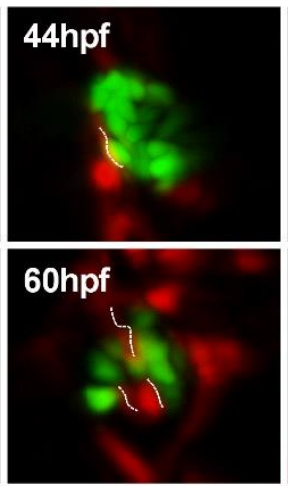

D

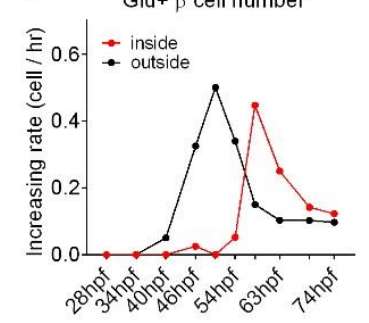

H

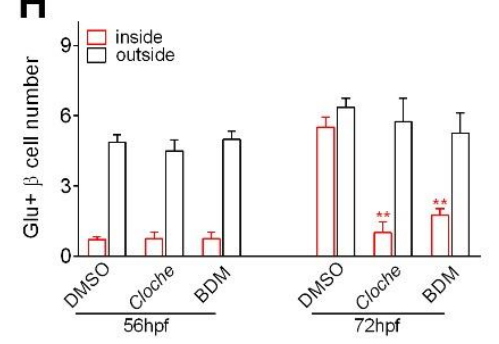

$\mathbf{E}$
B
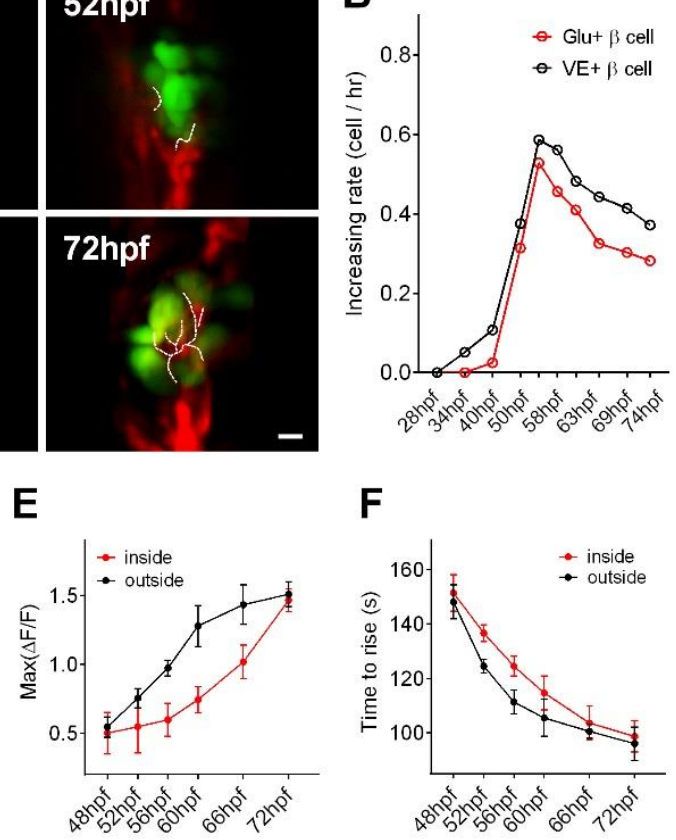

F

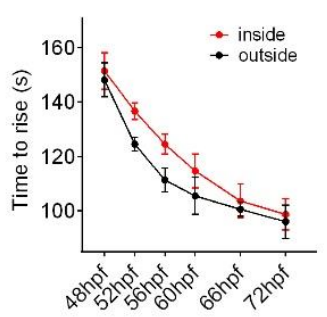

1

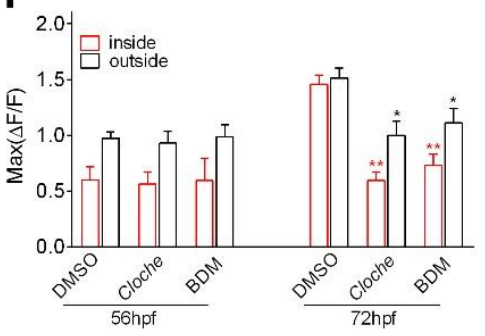




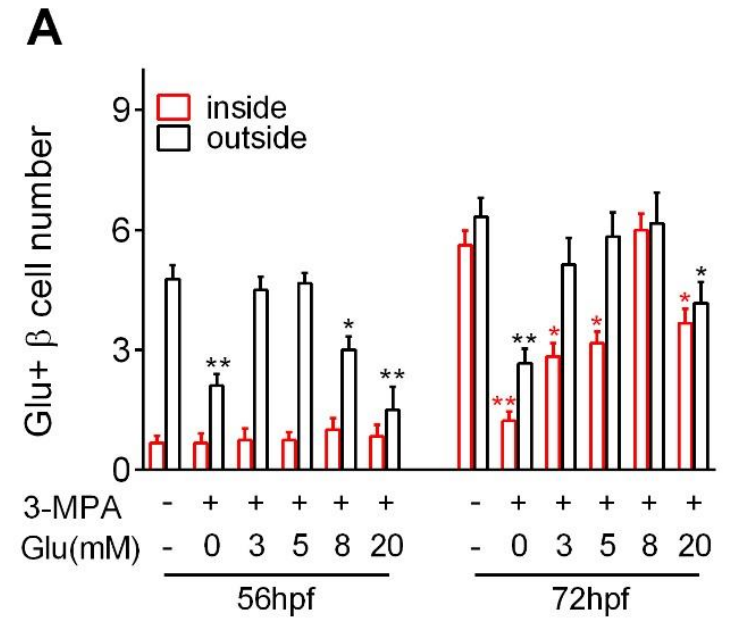

B

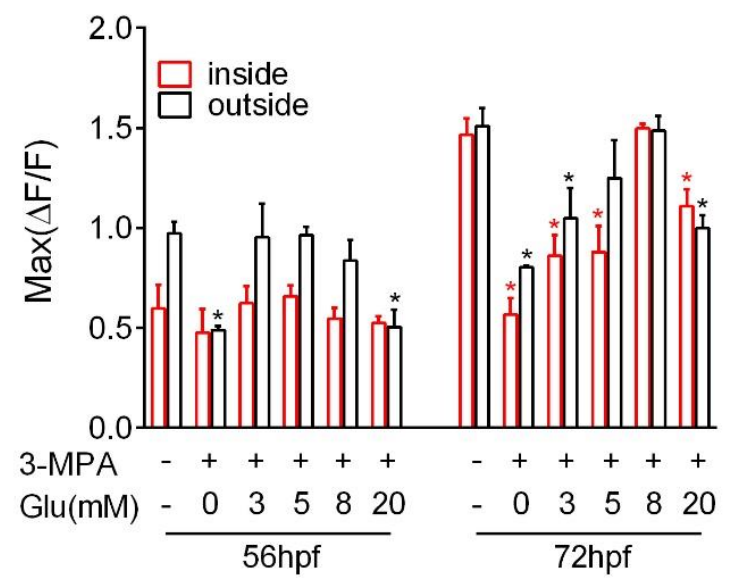

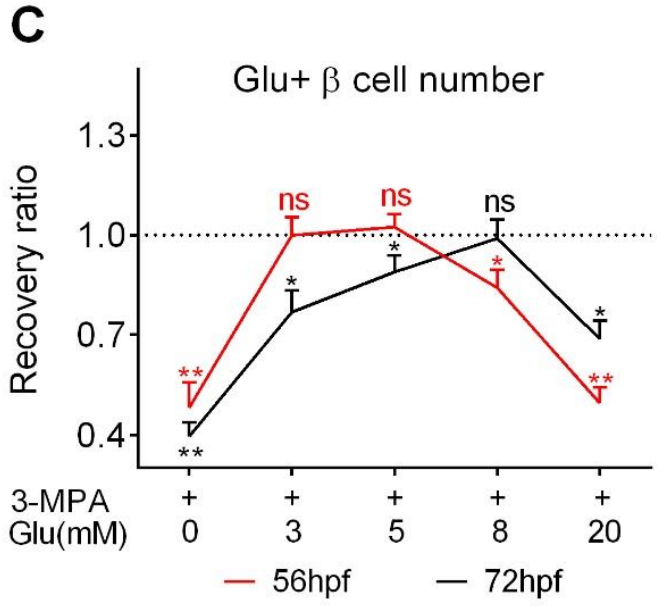

D

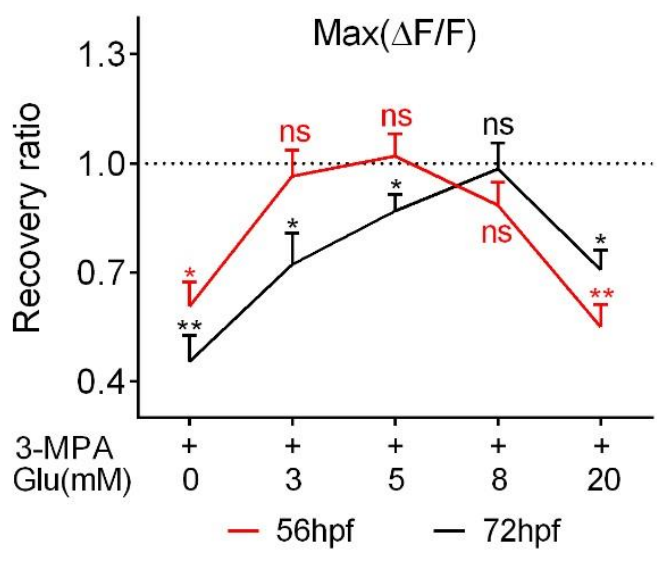


A

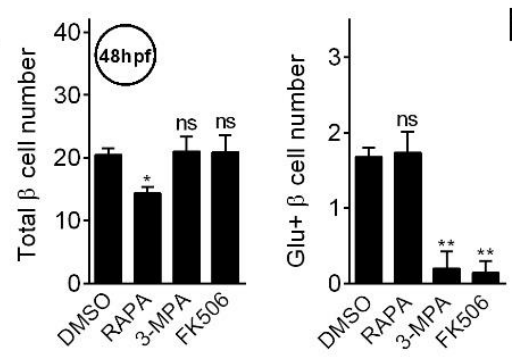

C
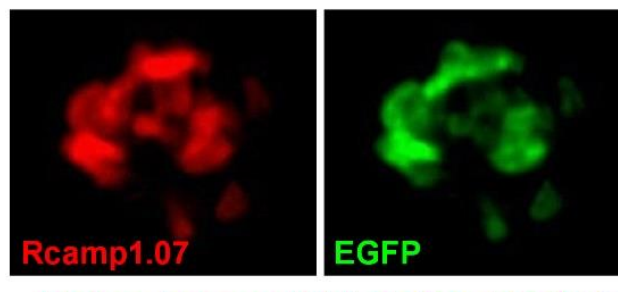

Tg(ins:Rcamp1.07); Tg(ins:EGFP-GSG-T2A-dn-ZCnA)

$\mathbf{F}$
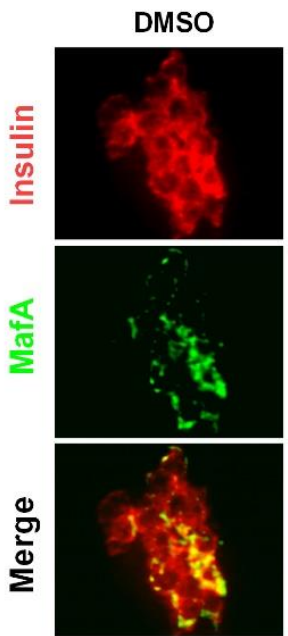

3-MPA
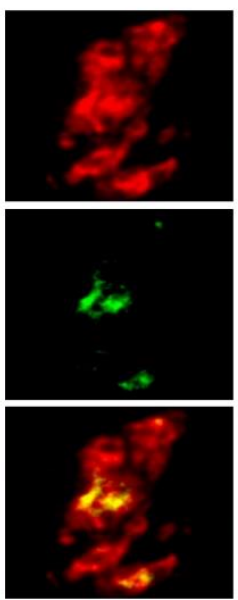

B
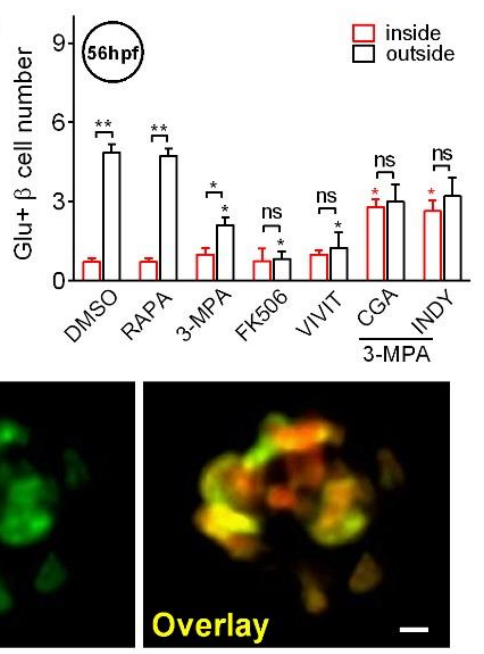

FK506

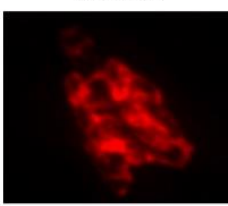

3-MPA+CGA
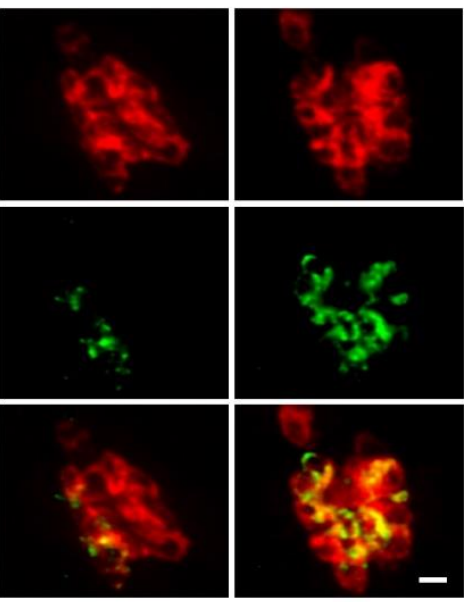

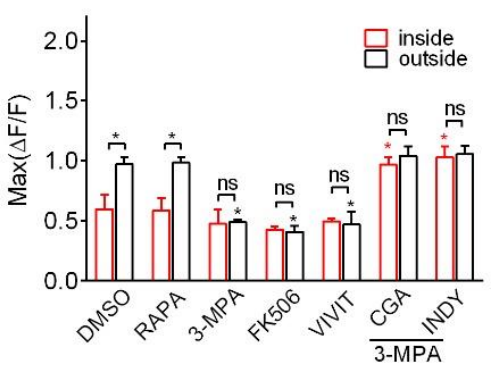

D

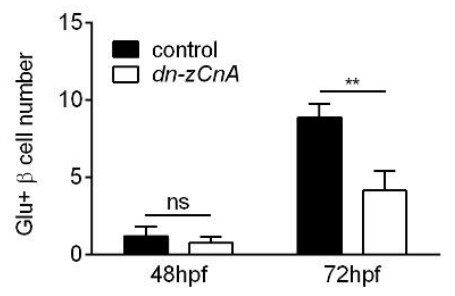

E

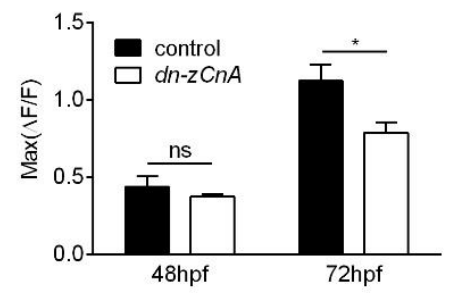

G

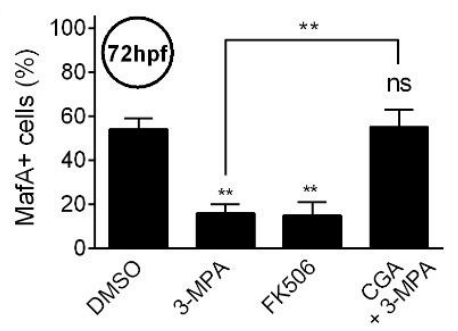




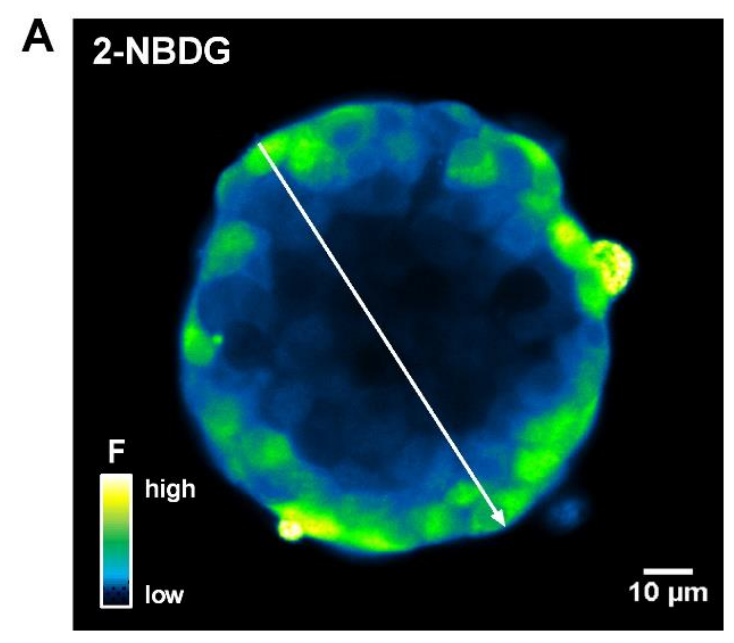

B

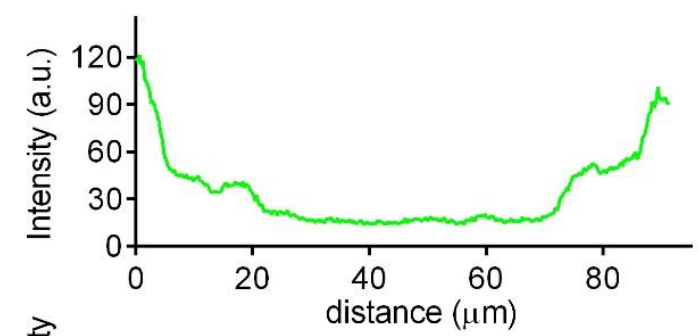

C
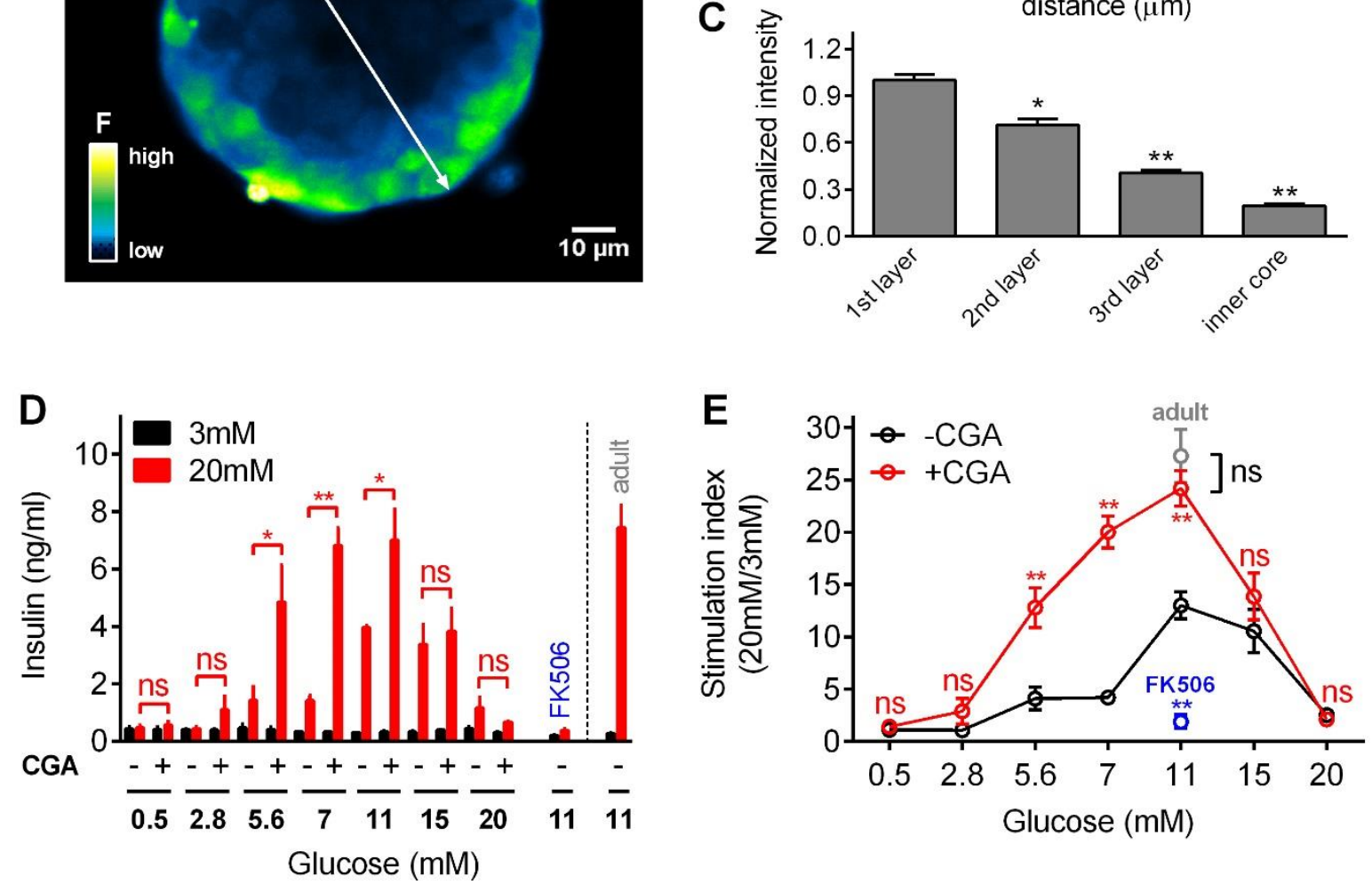


\section{Microcirculation-coordinated, Glucose-triggered, Calcineurin/NFAT-dependent $\beta$-cell Maturation in vivo}

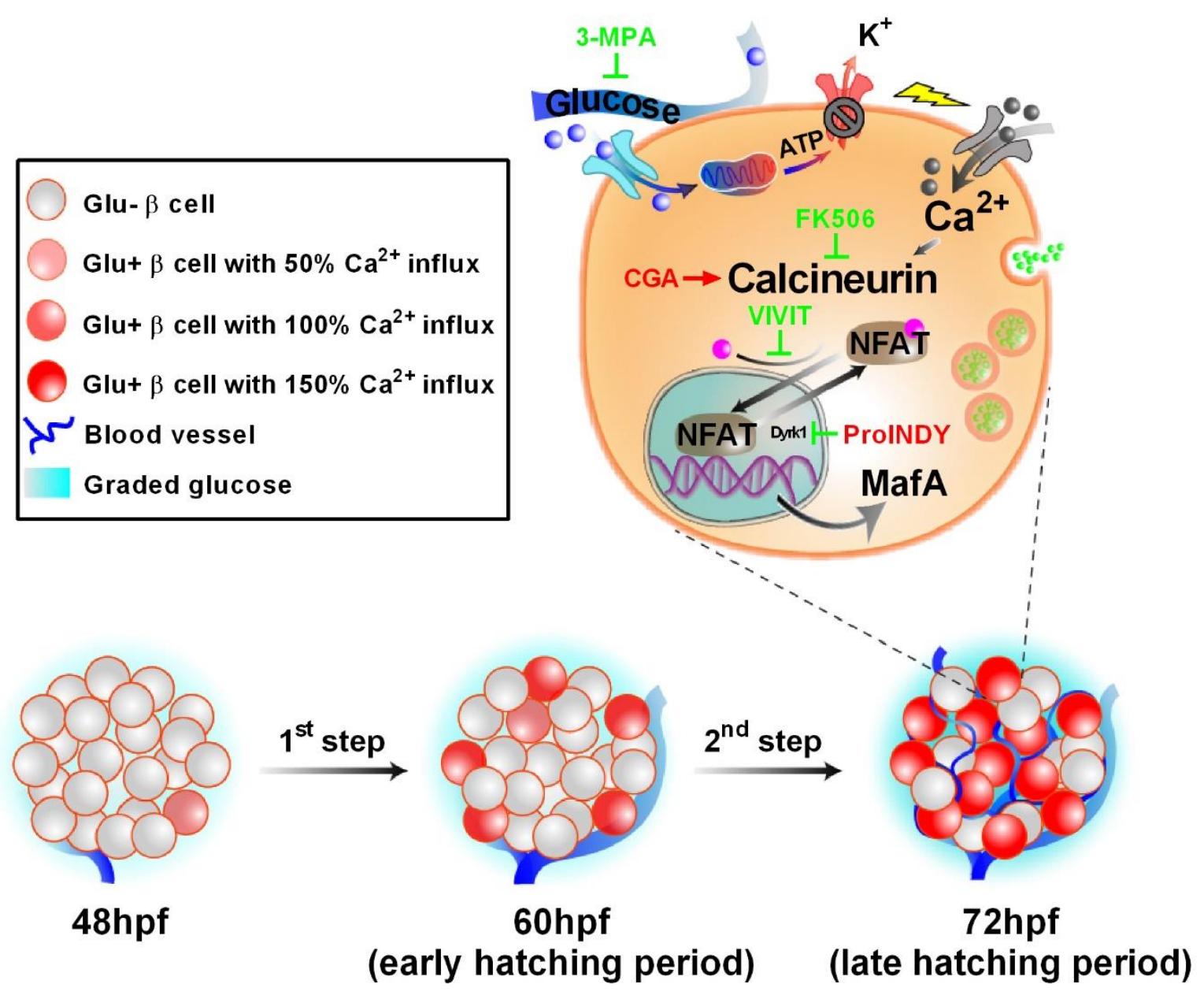


A

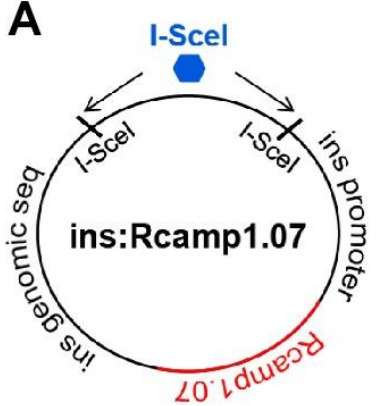

C

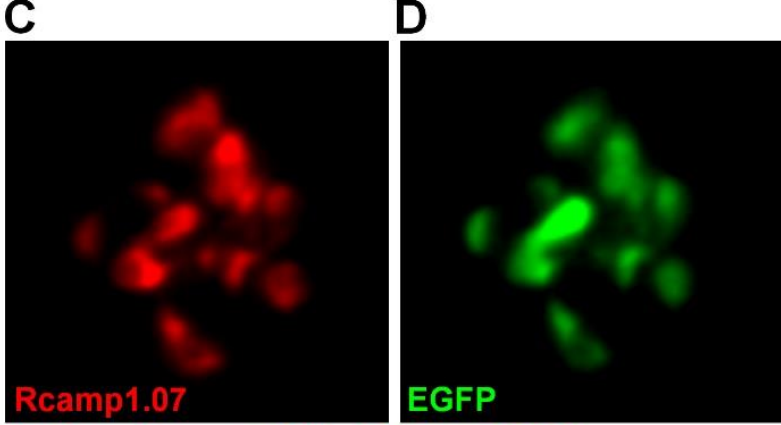

Tg(ins:Rcamp1.07);Tg(ins:EGFP)

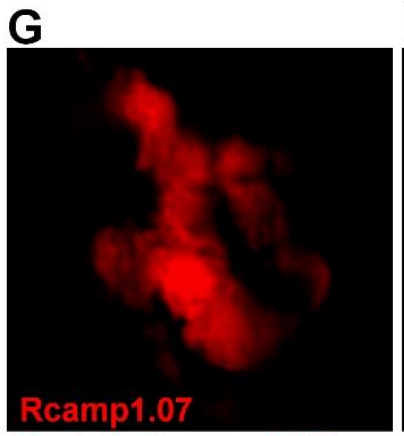

Tg(ins:Rcamp1.07)

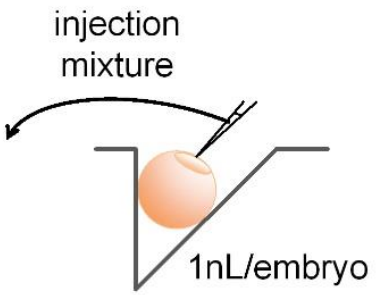

H
B
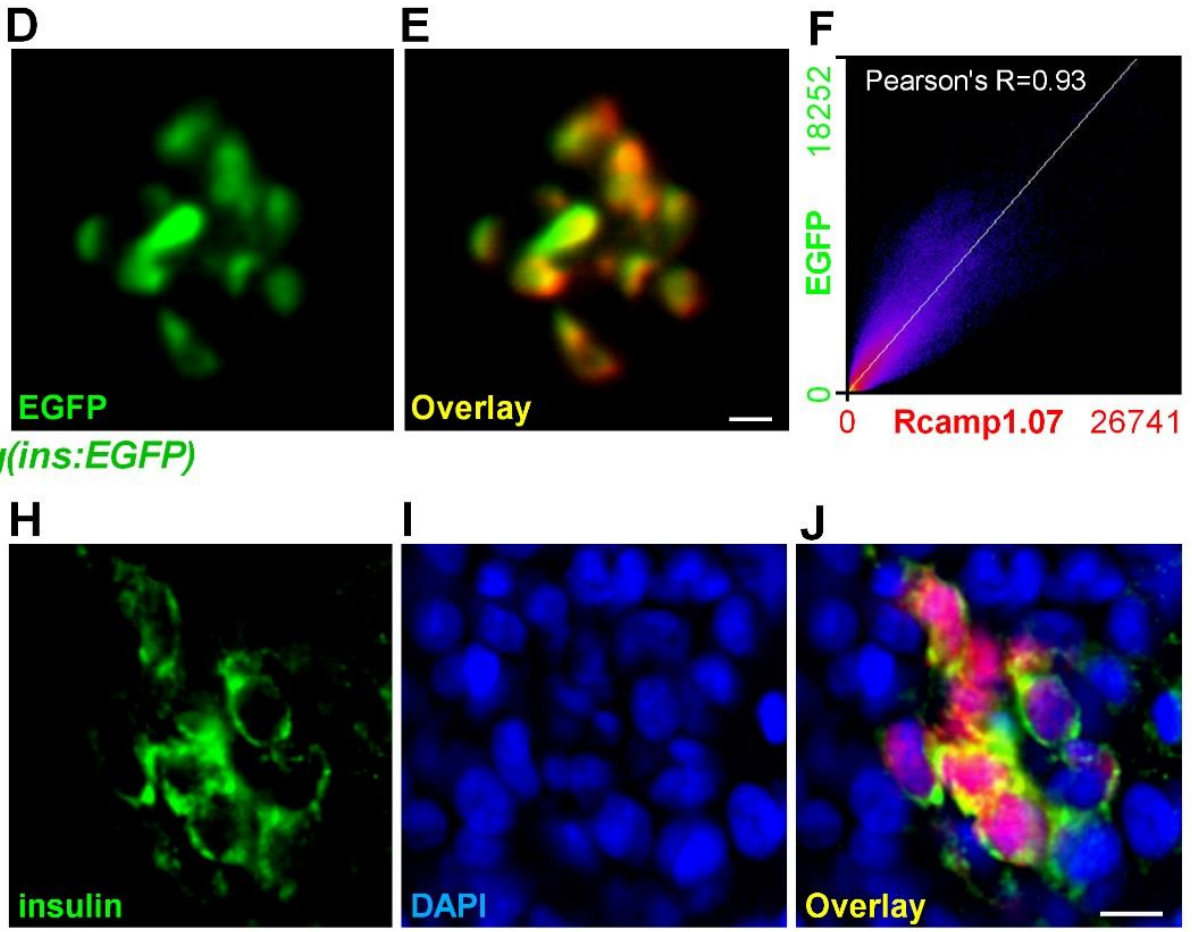

I

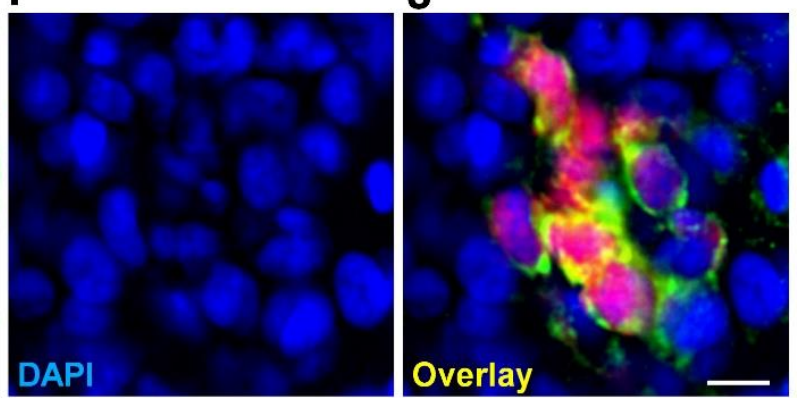


A
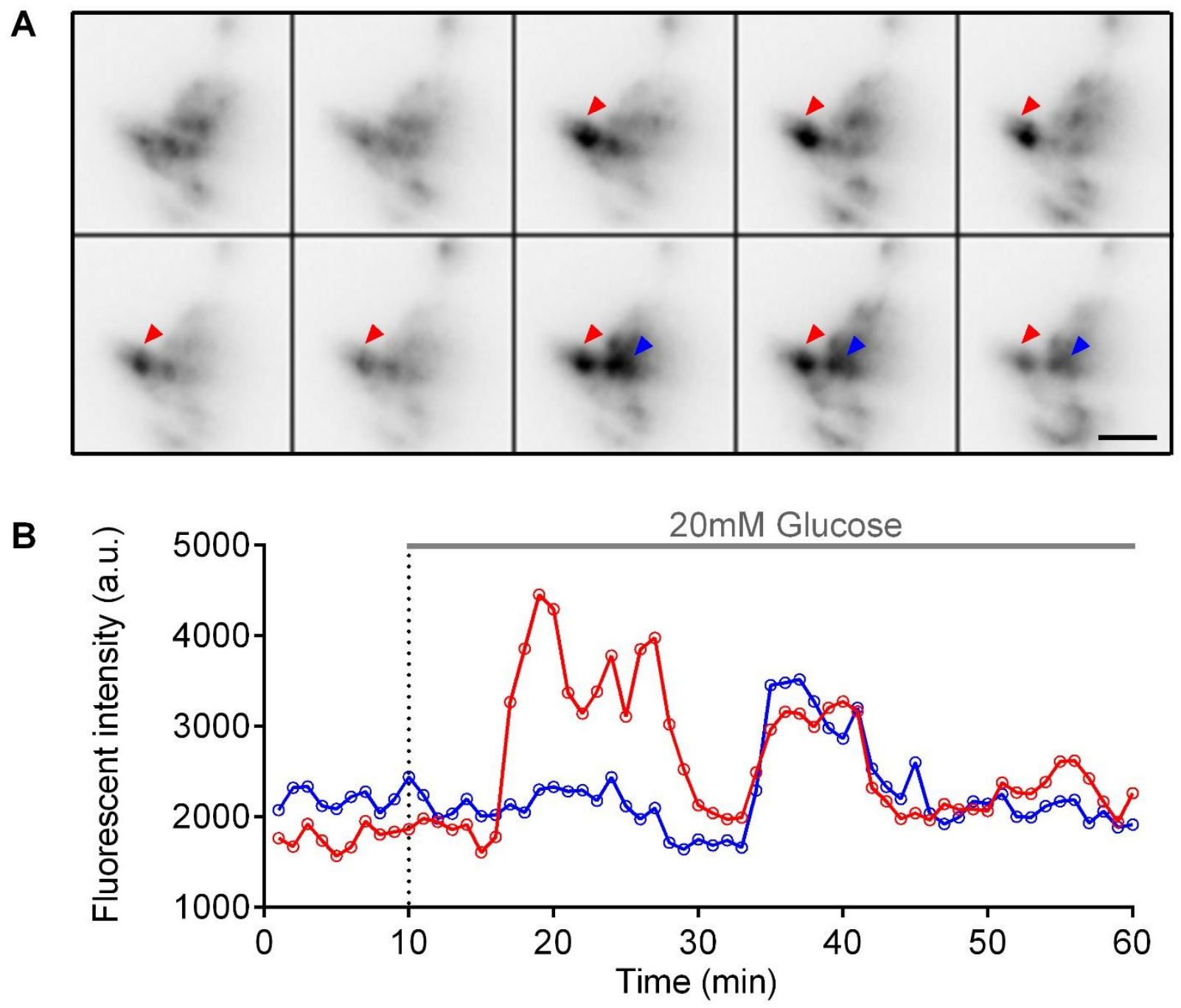
A

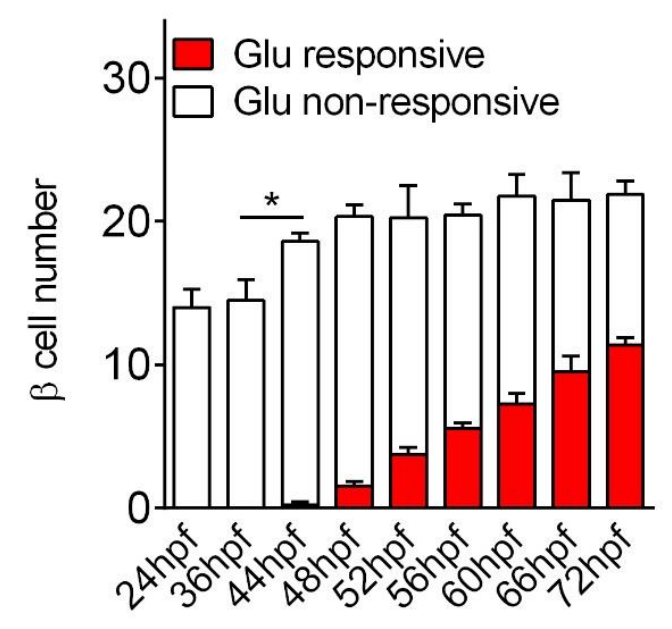

C

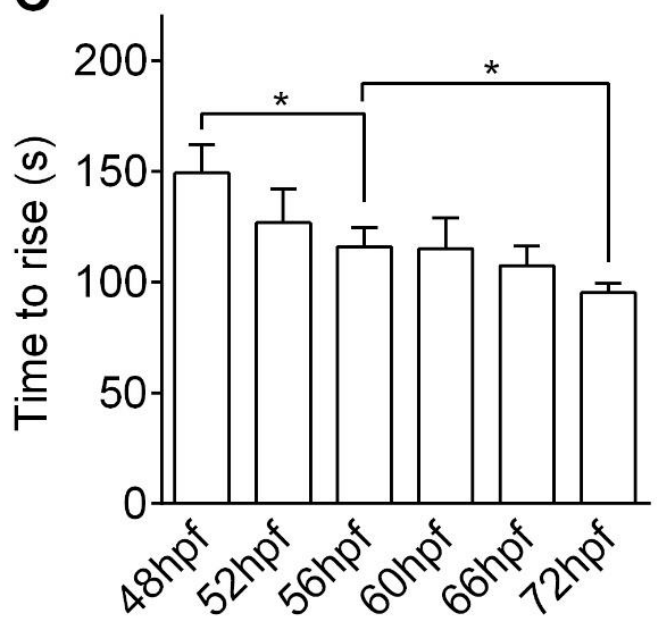

B

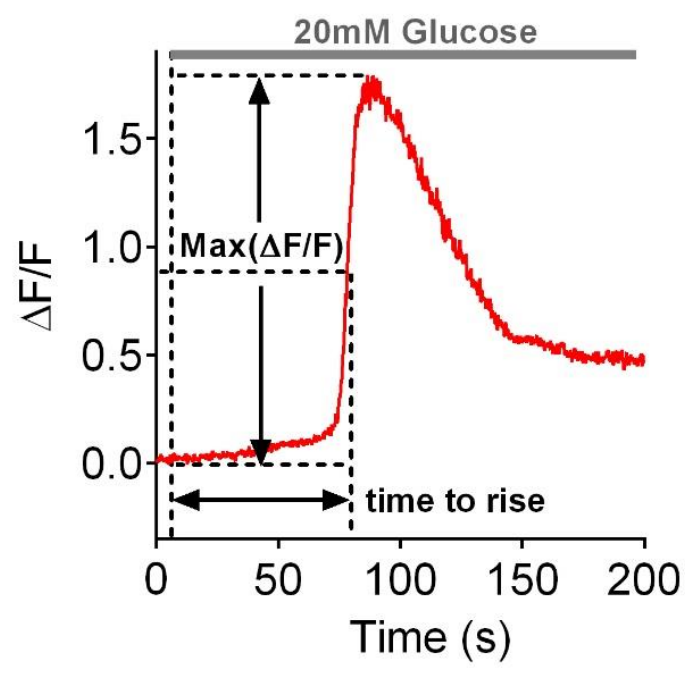

D

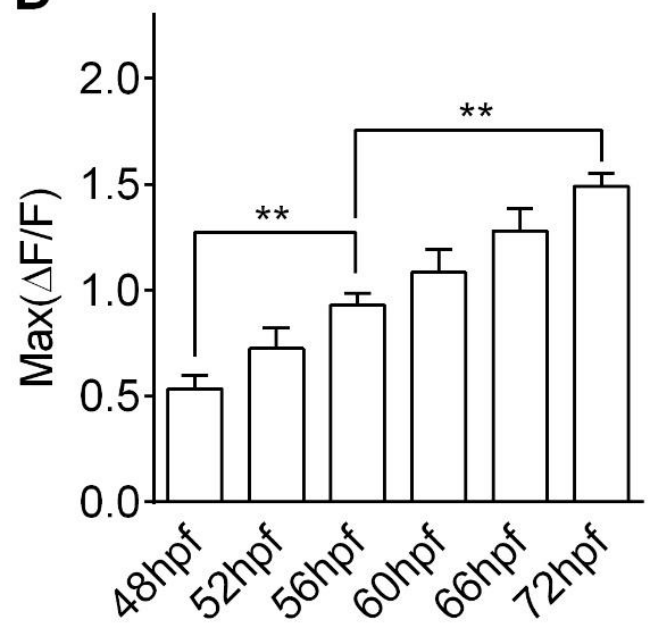




\section{A}

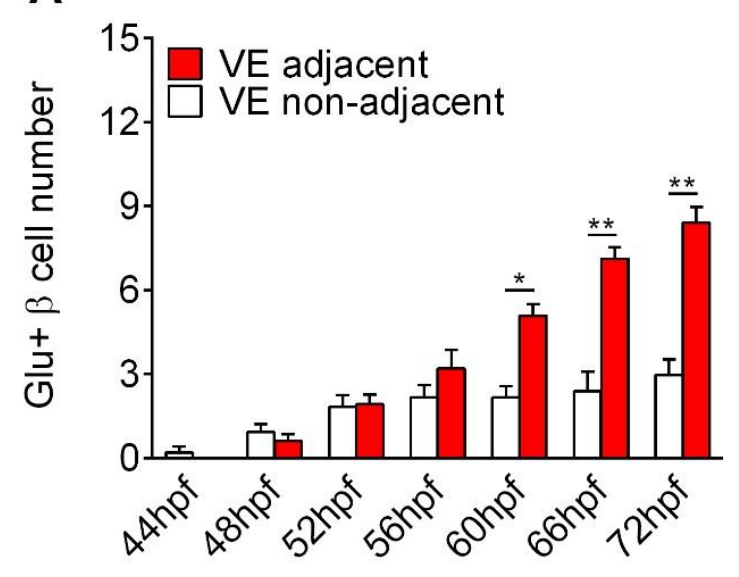

C

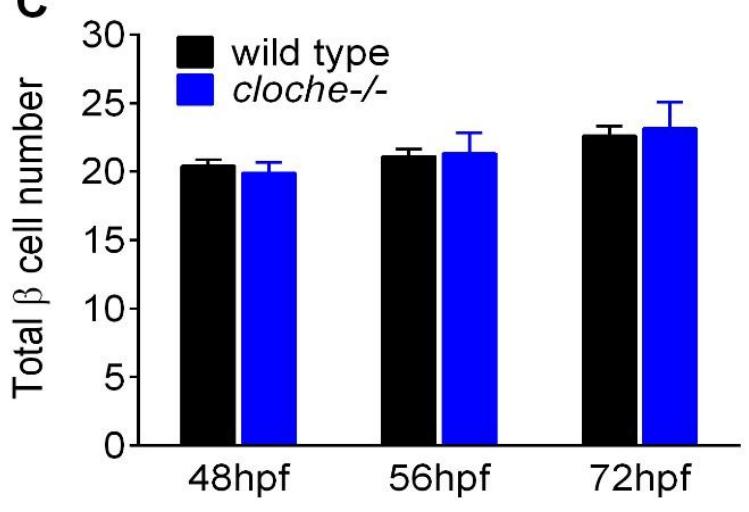

B

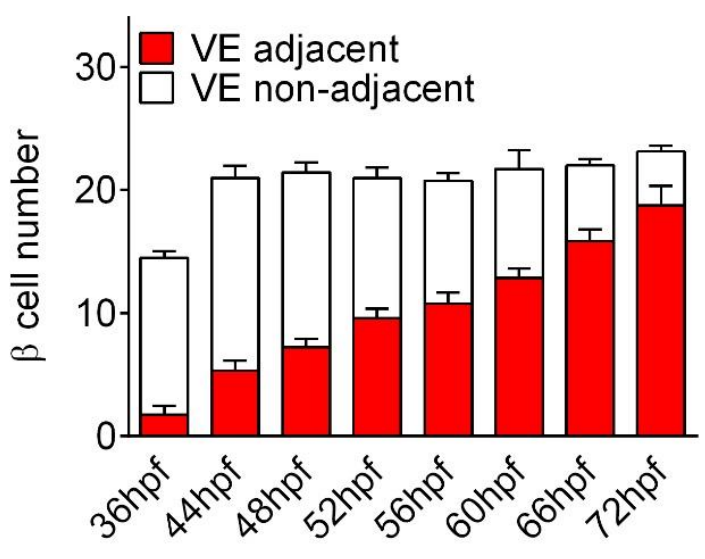


A Tg(ins:Rcamp1.07)

calcium imaging in vivo

\begin{tabular}{ll} 
drug treatment & wash out \\
\hline \hline $60 \mathrm{hpf}$ & $69 \mathrm{hpf}$
\end{tabular}

B

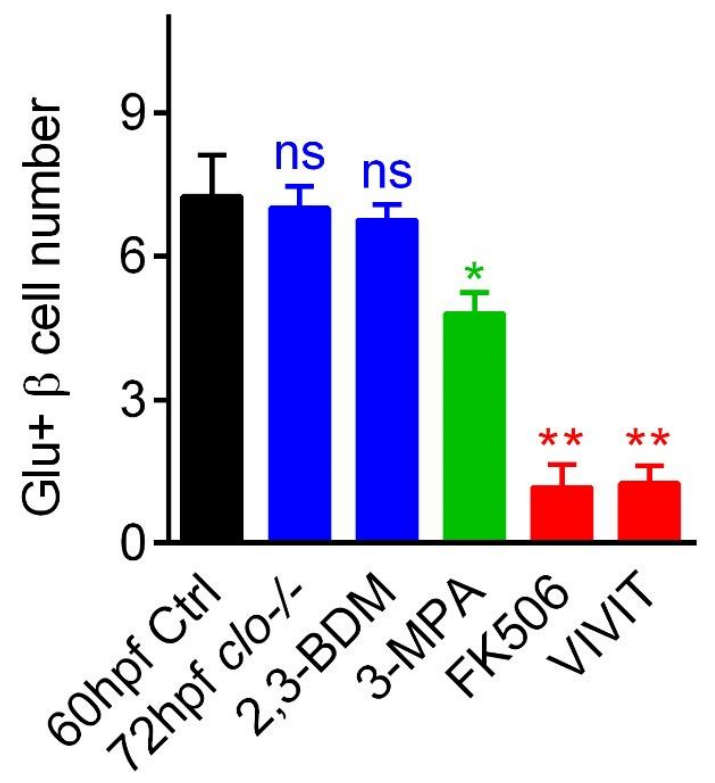

C

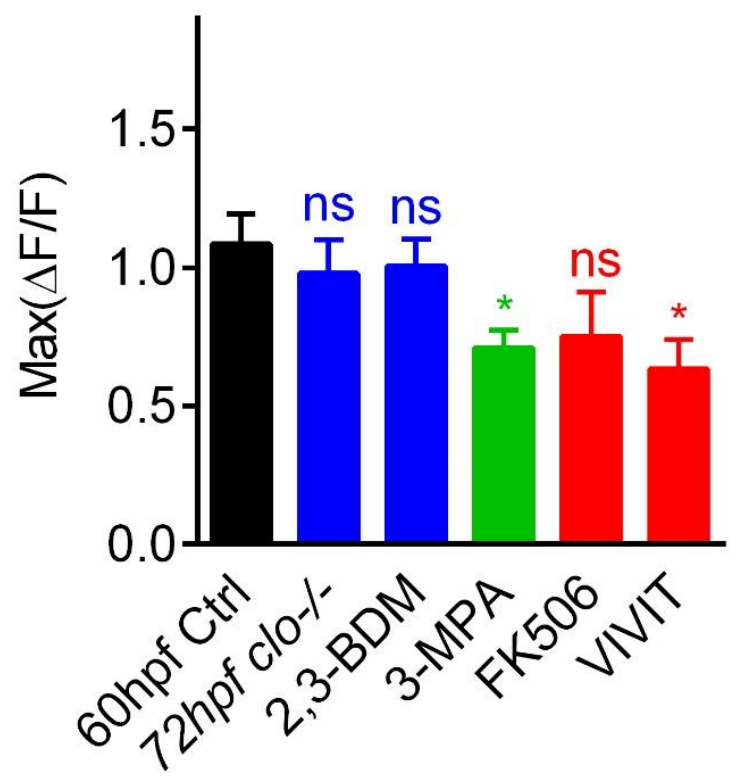


A

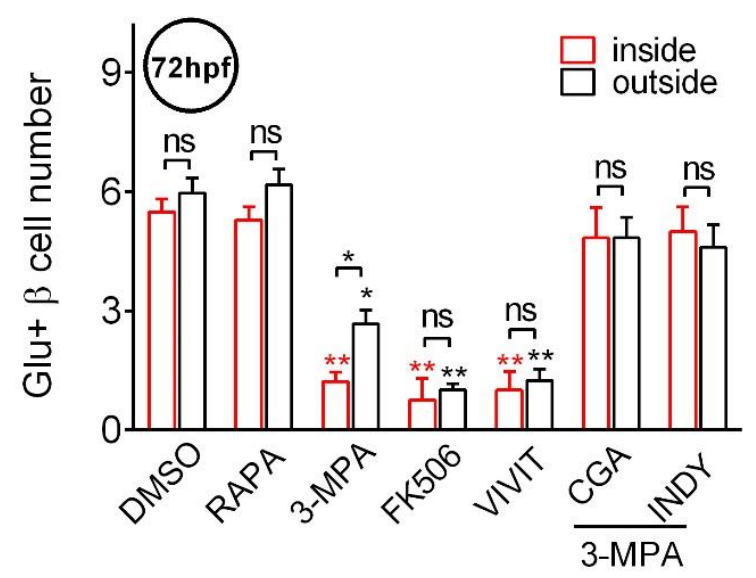

B

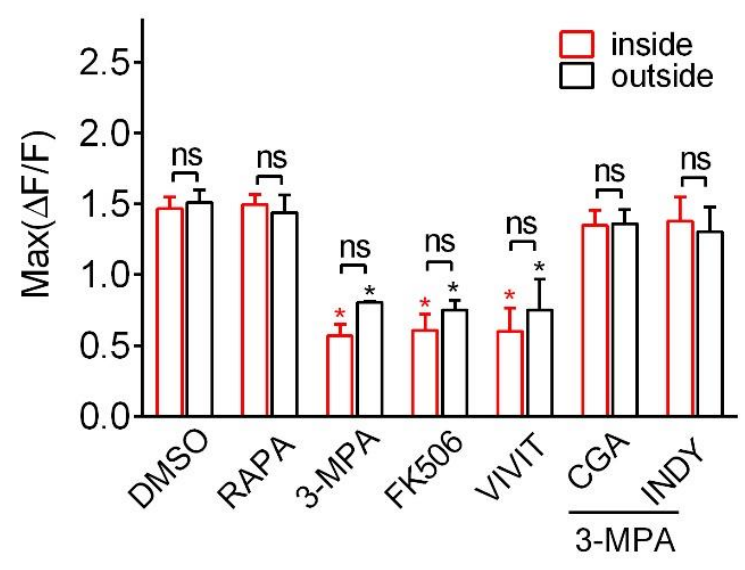


bioRxiv preprint doi: https://doi org/10.1101/159673; this version posted July 5, 2017. The copyright holder for this preprint (which was not certified by peer review) is the author/funder, who has granted bioRxiv a license to display the preprint in perpetuity. It is made available under aCC-BY 4.0 International license.

\begin{tabular}{|c|c|c|c|c|}
\hline \multirow{2}{*}{$\begin{array}{l}\text { Developmental } \\
\text { process }\end{array}$} & \multicolumn{4}{|c|}{ Comparison of events and critical time window in zebrafish and mouse pancreas development } \\
\hline & \multicolumn{2}{|l|}{ Zebrafish } & \multicolumn{2}{|l|}{ Mouse } \\
\hline $\begin{array}{l}\text { Pancreatic } \\
\text { specification }\end{array}$ & $P d x-1$ appears in pancreatic primordial (Tiso et al, 2009) & 10 somite & $P d x-1$ appears in dorsal endoderm (Shih et al, 2013) & E8-E8.5 \\
\hline $\begin{array}{l}\text { Islet } \\
\text { morphogenesis }\end{array}$ & $\begin{array}{l}\text { complete fusion of the two buds (Tehrani \& Lin, 2011; Tiso et } \\
\text { al, 2009) } \\
\text { principal islet forms core-mantle structure (Tehrani \& Lin, 2011; } \\
\text { Tiso et al, 2009) }\end{array}$ & $52-72 \mathrm{hpf}$ & condense islets form core-mantle structure (Shih et al, 2013) & $\mathrm{E} 18.5-\mathrm{E} 20$ \\
\hline $\begin{array}{l}\text { Islet } \\
\text { vascularization }\end{array}$ & $\begin{array}{l}\text { initiation with aorta contacting principal islet (Field et al, 2003b) } \\
\text { perfusion with blood flow in most vessels } \\
\text { fully vascularized principal islet }\end{array}$ & $\begin{array}{l}\text { 36-44hpf } \\
48-60 \mathrm{hpf} \\
66-72 \mathrm{hpf}\end{array}$ & $\begin{array}{l}\text { initiation with endocrine cell differentiation (Reinert et al, 2014; } \\
\text { Shah et al, 2011) } \\
\text { perfusion with blood flow in most vessels (Shah et al, 2011) } \\
\text { completed islet vascularization (Reinert et al, 2014) }\end{array}$ & $\begin{array}{l}\text { E13.5 } \\
\text { E14.5 } \\
\text { E20-at birth }\end{array}$ \\
\hline $\begin{array}{l}\beta \text {-cell } \\
\text { differentiation }\end{array}$ & $\begin{array}{l}\text { emergence of insulin-positive cells (Tehrani \& Lin, 2011; Tiso } \\
\text { et al, 2009) } \\
\beta \text {-cell proliferation (independent of Cn/NFAT) (Tsuji et al, 2014) } \\
\text { appearance of glucose-responsive } \beta \text {-cells } \\
\beta \text {-cell functional maturing }\end{array}$ & $\begin{array}{l}15 \text { somite } \\
\text { 36-40hpf } \\
44-48 \mathrm{hpf} \\
48-72 \mathrm{hpf}\end{array}$ & $\begin{array}{l}\text { emergence of insulin-positive cells (Yamaoka \& Itakura, 1999) } \\
\text { rapid expansion of } \beta \text {-cells (independent of Cn) (Goodyer et al, } \\
\text { 2012b; Shah et al, 2011) } \\
\text { appearance of glucose-responsive } \beta \text {-cells (Hole et al, 1988; } \\
\text { Reinert et al, 2014; Rozzo et al, 2009) } \\
\beta \text {-cell functional maturation (Blum et al, 2012a) }\end{array}$ & $\begin{array}{l}\text { E9.5-E10.5 } \\
\text { E14.5 } \\
\text { P2 } \\
\text { P9 }\end{array}$ \\
\hline
\end{tabular}

